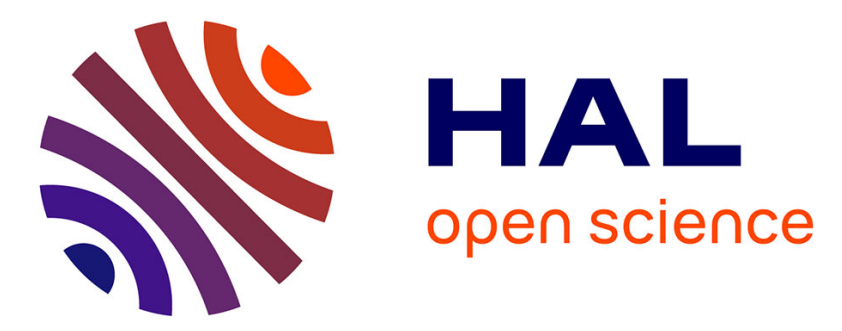

\title{
Joint economic optimization of heat exchanger design and maintenance policy
}

Antonio C. Caputo, Pacifico M. Pelagagge, Paolo Salini

\section{To cite this version:}

Antonio C. Caputo, Pacifico M. Pelagagge, Paolo Salini. Joint economic optimization of heat exchanger design and maintenance policy. Applied Thermal Engineering, 2011, 31 (8-9), pp.1381. 10.1016/j.applthermaleng.2010.12.033 . hal-00730289

\section{HAL Id: hal-00730289 \\ https://hal.science/hal-00730289}

Submitted on 9 Sep 2012

HAL is a multi-disciplinary open access archive for the deposit and dissemination of scientific research documents, whether they are published or not. The documents may come from teaching and research institutions in France or abroad, or from public or private research centers.
L'archive ouverte pluridisciplinaire HAL, est destinée au dépôt et à la diffusion de documents scientifiques de niveau recherche, publiés ou non, émanant des établissements d'enseignement et de recherche français ou étrangers, des laboratoires publics ou privés. 


\section{Accepted Manuscript}

Title: Joint economic optimization of heat exchanger design and maintenance policy

Authors: Antonio C. Caputo, Pacifico M. Pelagagge, Paolo Salini

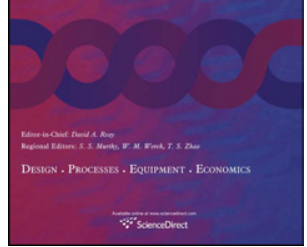

PII:

S1359-4311(11)00002-0

DOI:

10.1016/j.applthermaleng.2010.12.033

Reference:

ATE 3357

To appear in: Applied Thermal Engineering

Received Date: 11 January 2010

Revised Date: 3 November 2010

Accepted Date: 22 December 2010

Please cite this article as: A.C. Caputo, P.M. Pelagagge, P. Salini. Joint economic optimization of heat exchanger design and maintenance policy, Applied Thermal Engineering (2011), doi: 10.1016/ j.applthermaleng.2010.12.033

This is a PDF file of an unedited manuscript that has been accepted for publication. As a service to our customers we are providing this early version of the manuscript. The manuscript will undergo copyediting, typesetting, and review of the resulting proof before it is published in its final form. Please note that during the production process errors may be discovered which could affect the content, and all legal disclaimers that apply to the journal pertain. 


\section{JOINT ECONOMIC OPTIMIZATION OF HEAT EXCHANGER DESIGN AND \\ MAINTENANCE POLICY}

Antonio C. Caputo - acaputo@ uniroma3.it ${ }^{1}$

Department of Mechanical and Industrial Engineering,

University of Roma Tre, Italy.

Pacifico M. Pelagagge - pacifico.pelagagge@ univaq.it

Paolo Salini - paolo.salini@univaq.it

Department of Mechanical, Energy and Management Engineering, University of L'Aquila, Italy.

Abstract. In this paper a new approach to shell and tube heat exchanger optimization is presented based on the minimization of the life-cycle cost. The method allows the joint optimization of both the equipment design and the cleaning policy. Economic savings resulting from the proposed design procedure are relevant especially when large sized equipment is involved or when a large number of small sized units are installed. At first, a thermal design procedure defines the heat transfer area as well as flow velocities and the fouling rate, given the heat duty of the equipment. The capital investment, pressure losses and the cleaning interval required to reach a maximum allowed fouling resistance are thus calculated. An optimization algorithm is then utilized to determine the optimal values of both geometric design parameters and maximum allowable fouling resistance by pursuing the minimization of a total cost function. The objective function includes capital investment, operational costs related to friction losses, and maintenance costs deriving from the cleaning schedule. The research contribution comes from integrating two optimization tasks which traditionally are carried out in separate ways.

\footnotetext{
${ }^{1}$ University of Roma Tre, Department of Mechanical and Industrial Engineering, Via della Vasca Navale, 79 - 00146 Roma, Italy (phone: +39-06 57333546; e-mail: acaputo@ uniroma3.it).
} 
In fact, during the design phase the heat exchanger architecture is usually optimized

neglecting maintenance expenses, while during the operational phase the heat ex-

changer architecture is already finalized and maintenance optimization approaches al-

low only to determine a minimum cost cleaning schedule based on the existing ex-

changer. In this work, instead, the problems of equipment sizing and cleaning schedule

determination are solved simultaneously so that the entire life cycle cost is minimized.

Optimization of the objective function is carried out resorting to a genetic algorithm. In

the paper the optimal design approach is described and an application example is pro-

vided to show the capability of the method.

Keywords: heat exchangers, fouling, genetic algorithm, cleaning, optimization.

\section{NOMENCLATURE}

\begin{tabular}{|c|c|c|}
\hline$a_{j}$ & Binary activation index & {$[-]$} \\
\hline $\mathrm{B}_{\mathrm{c}}$ & Baffle cut & {$[\%]$} \\
\hline $\mathrm{C}_{\mathrm{AUX}}$ & Aquxiliary energy related cost of cleaning operation & [€/cleaning] \\
\hline $\mathrm{C}_{\text {clean }}$ & Unit cost of cleaning operation & [€/cleaning] \\
\hline $\mathrm{C}_{\text {clean,tot }}$ & Cleaning cost present value & {$[€]$} \\
\hline $\mathrm{C}_{\mathrm{E}}$ & Energy related expense for heat transfer reduction over time between cleaning & [€/cleaning] \\
\hline $\mathrm{C}_{\mathrm{es}}$ & Operating cost & {$[€ / y r]$} \\
\hline $\mathrm{C}_{\mathrm{es} \text {,tot }}$ & Operating cost present value & {$[€]$} \\
\hline $\mathrm{C}_{\text {fitt }}$ & Fictious penalty cost & {$[€]$} \\
\hline $\mathrm{C}_{\mathrm{I}}$ & Capital investment & {$[€]$} \\
\hline $\mathrm{C}_{\mathrm{M}}$ & Miscellaneous maintenance related cost & [€/cleaning] \\
\hline $\mathrm{C}_{\text {tot }}$ & Total life cycle cost & {$[€]$} \\
\hline $\mathrm{D}_{\mathrm{s}}$ & Internal shell diameter & {$[\mathrm{mm}]$} \\
\hline$D_{t}$ & Tubes external diameter & {$[\mathrm{mm}]$} \\
\hline $\mathrm{D}_{\mathrm{ti}}$ & Tubes internal diameter & {$[\mathrm{mm}]$} \\
\hline$f^{\prime \prime}$ & Inflation rate & [\%/year] \\
\hline $\mathrm{L}_{\mathrm{bc}}$ & Central baffle spacing & {$[\mathrm{mm}]$} \\
\hline $\mathrm{L}_{\mathrm{bi}}, \mathrm{L}_{\mathrm{bo}}$ & Extremal baffles spacing & {$[\mathrm{mm}]$} \\
\hline $\mathrm{L}_{\mathrm{tp}}$ & Tubes pitch & {$[\mathrm{mm}]$} \\
\hline $\mathrm{L}_{\mathrm{tpRatio}}$ & Pitch ratio & {$[\%]$} \\
\hline $\mathrm{L}_{\mathrm{tt}}$ & Tubes length & {$[\mathrm{mm}]$} \\
\hline $\mathrm{N}$ & Overall cleanings number & {$[-]$} \\
\hline $\mathrm{N}_{\mathrm{b}}$ & Number of baffles & {$[-]$} \\
\hline $\mathrm{N}_{\text {clean }}$ & Number of annual cleaning operations & [year ${ }^{-1}$ ] \\
\hline $\mathrm{N}_{\mathrm{ss}}$ & Sealing strips number & {$[-]$} \\
\hline $\mathrm{N}_{\mathrm{tp}}$ & Tube passes & {$[-]$} \\
\hline $\mathrm{N}_{\mathrm{tt}}$ & Tubes number & {$[-]$} \\
\hline Nyr & Equipment life & [years] \\
\hline$P_{j}$ & Binary violation index & {$[-]$} \\
\hline
\end{tabular}




\section{$\operatorname{Pr}_{\mathrm{s}}$}

$\mathrm{Pr}_{\mathrm{t}} \quad$ Prandtl number (tube-side)

$\mathrm{R}_{\mathrm{f}} \quad$ Fouling resistance

$R_{f o} \quad$ Shell-side fouling resistance

$\mathrm{R}_{\mathrm{f} \mathrm{i}} \quad$ Tube-side fouling resistance

$\mathrm{R}_{\mathrm{f} \text { all } \quad \text { Allowed fouling resistance }}$

$\mathrm{R} *_{\mathrm{f}} \quad$ Asymptotic fouling resistance

$\mathrm{Re}_{\mathrm{s}} \quad$ Reynolds number (shell-side)

$\mathrm{Re}_{\mathrm{t}} \quad$ Reynolds number (tube-side)

$\mathrm{S} \quad$ Interest rate

S Actual heat exchange surface area

$\mathrm{S}_{\text {clean }} \quad$ Basic heat exchange surface area

$\mathrm{S}_{\text {extra }} \quad$ Additional heat exchange surface area

$\mathrm{T}_{\text {is }} \quad$ Shell-side inlet temperature

$\mathrm{T}_{\text {os }} \quad$ Shell-side outlet temperature

$\mathrm{T}_{\text {it }} \quad$ Tube-side inlet temperature

$\mathrm{T}_{\text {ot }} \quad$ Tube-side outlet temperature

$\mathrm{T}_{\text {clean }} \quad$ Cleaning interval

$\mathrm{v}_{\mathrm{s}}$

$\mathrm{V}_{\mathrm{t}}$

Greek Symbols

$\alpha_{\mathrm{s}} \quad$ Convective heat transfer coefficient (shell-side)

$\alpha_{t} \quad$ Convective heat transfer coefficient (tube-side)

$\beta \quad$ Reciprocal of the fouling time constant

$\Delta \mathrm{p}_{\mathrm{s}} \quad$ Pressure drop (shell-side)

$\Delta \mathrm{p}_{\mathrm{t}} \quad$ Pressure drop (tube-side)

$\theta_{\mathrm{tp}} \quad$ Tube layout angle

$\lambda_{\mathrm{w}} \quad$ Thermal conductivity of tube walls

$\varphi_{\mathrm{d}} \quad$ Fouling deposit growth rate

$\varphi_{\mathrm{r}} \quad$ Fouling deposit removal rate
$[-]$

[-]

$\left[\mathrm{m}^{2} \mathrm{~K} / \mathrm{W}\right]$

$\left[\mathrm{m}^{2} \mathrm{~K} / \mathrm{W}\right]$

$\left[\mathrm{m}^{2} \mathrm{~K} / \mathrm{W}\right]$

$\left[\mathrm{m}^{2} \mathrm{~K} / \mathrm{W}\right]$

$\left[\mathrm{m}^{2} \mathrm{~K} / \mathrm{W}\right]$

[-]

[-]

[\%/year]

$\left[\mathrm{m}^{2}\right]$

$\left[\mathrm{m}^{2}\right]$

[\%]

[K]

[K]

[K]

[K]

[h]

$\left[\mathrm{W} / \mathrm{m}^{2} \mathrm{~K}\right]$

$[\mathrm{m} / \mathrm{s}]$

$[\mathrm{m} / \mathrm{s}]$

$\left[\mathrm{W} / \mathrm{m}^{2} \mathrm{~K}\right]$

$\left[\mathrm{W} / \mathrm{m}^{2} \mathrm{~K}\right]$

$\left[\right.$ day $\left.^{-1}\right]$

[kPa]

[kPa]

[deg]

[W/m K]

$\left[\mathrm{m}^{2} \mathrm{~K} / \mathrm{W} \mathrm{s}\right]$

$\left[\mathrm{m}^{2} \mathrm{~K} / \mathrm{W} \mathrm{s}\right]$

\section{INTRODUCTION}

In recent times a renewed interest in the optimal design of heat exchangers has been witnessed in the literature. This results from the availability of new optimization techniques, such as genetic algorithms, able to handle a large number of design parameters including both discrete and continuous variables. Considering the functional importance and widespread utilization of heat exchangers in process plants, their minimum cost design is also an important goal. In particular, the minimization of energy related expenses is critical in the optic of energy savings and resources conservation. However, given that most of the life cycle cost of an exchanger is made up of operational costs, includ- 
ing periodic cleaning to control fouling phenomena which deteriorate heat transfer, even the optimization of maintenance schedules is a relevant problem. This applies either in case of single large sized units and in case of multiple smaller sized units installed in a process plant, where prospective economic savings can be relevant. For instance, Kuppan [1] reports that the economic loss due to fouling in heat exchangers is about 1 G\$/yr for American plants, whereas in Hewitt [2] an estimate of economic loss up to 1.4 G\$/yr for U.S.A. and between 0.5 and $1 \mathrm{M} \$$ for English plants is given. Passing to more specific examples, Polley et al. [3] report the case of a $10 \mathrm{MW}$ exchanger processing $100.000 \mathrm{bbl}$ of crude oil per day located at the hot end of a preheat train, which could cumulate a loss of $\$ 100.000$ after 2000 h (three months) of operation, while Putman [4] reports that about $\$ 265.000$ annual losses can result from a 450 MW steam condenser without cleaning.

Nevertheless, in the literature two basically different approaches have been pursued as far as heat exchanger optimization is concerned. The first approach is aimed at the optimal sizing of the heat exchanger usually based on a cost minimization goal, considering capital investment and energy related expenses, or on the maximization of some thermal performance. In this approach the impact of periodical cleaning of the exchanger is neglected and fouling phenomena are considered only by including a predefined allowance for a fouling resistance in the thermal design procedure. The second approach, instead, assumes that the heat exchanger has been already built and that a maintenance schedule has to be optimized in order to minimize maintenance and energy related costs while satisfying the required heat duty.

Recent examples of design optimization methods are the works of Khalifeh Soltan et al. [5], Unuvar and Kargici [6], Selbas et al. [7], Sena-Gonzalez et al. [8], Ponce-Ortega 
et al. [9], Costa and Queiroz [10], and the optimization techniques utilized nowadays in heat exchangers optimization are frequently of genetic nature $[7,11,12,13]$. Although some scholars are skeptical about the use of precise optimization methods when applied to heat exchanger design, owing to the inherent fuzziness of the problem given the uncertainty in operating conditions and in the adopted design correlations [14], computer based optimization of heat exchanger design is an established and widely accepted research subject. When evaluating a cost based objective function, the investment cost has been usually estimated resorting to literature correlations [15], even if the inconsistency of utilizing simplified parametric cost functions in detailed design optimization procedures has been demonstrated by Caputo et al. [16,17], whereas the operating cost is always considered as an energy related cost, imputable to overcoming friction losses in the fluid flow.

Examples of maintenance schedule optimization approaches are provided, instead, by Putman [18], Khan and Zubair [19], O’Donnell et al. [20], Sheikh et al. [21], Zubair et al. [22], Zubair and Shah [23]. However, in this field a large contribution has been made to maintenance of heat exchanger networks [24-33]. Some scholars also attempted to include maintenance concerns in a design optimization procedure. For instance, WildiTremblay and Gosselin [34] included a minimum surface area constraint to account for fouling within a genetic optimization procedure. A different approach was chosen, instead, by Butterworth [35] who adopted the "design envelope" sizing method utilizing a fouling resistance which is dependent on velocity and temperature within the heat exchanger in order to find an arrangement which allows the exchanger to operate below the fouling threshold. Similarly, Polley et al. [3] and Wilson et al. [36] modified the Poddard plot design method to identify a fouling threshold and design the exchanger to operate below that threshold so that fouling can be virtually eliminated. This could be made by changing the thermal contacting arrangement, by increasing the tube-side ve- 
locity (within a prescribed maximum pressure drop threshold), and by decreasing the shell side heat transfer coefficient [36]. However, to operate below the fouling threshold often results in higher fluid velocities. Therefore, while the described approach allows to avoid any fouling related expenses (i.e. heat exchanger cleaning and additional fluid consumption in auxiliary heaters) the fact that pressure drop related energy expenses are not explicitly factored in does not guarantee that a design minimizing the life cycle cost is obtained. Finally, Fryer et al. [37] discuss fouling impact on heat exchanger design in the case of milk fouling, while Branch et al. [38] consider the case of crystallization fouling.

In order to overcome the drawbacks of the current two-step approach (optimal design neglecting maintenance and subsequent optimization of the cleaning schedule for an existing exchanger), in this work a method for joint optimization of both the equipment design and the cleaning policy is described. A genetic algorithm is utilized to determine the optimal values of both geometric design parameters (i.e. shell diameter, tubes diameter, pitch pattern etc.) and the maximum allowable fouling resistance so that the minimization of a total cost function including capital investment, operational costs related to friction losses, and fouling related costs deriving from the cleaning schedule is obtained. In this manner a more precise approach respect that of previous literature works [34] is obtained in that an overall cost minimization is pursued without imposing any predetermined constraint on the exchanger surface area, while pumping energy expenses and maintenance costs are explicitly included so that a minimization of life cycle cost can be pursued as an alternative to looking for fouling free operation $[3,35]$. Furthermore, the proposed approach enables to overcome some of the limitations of traditional optimization methods which, when neglecting fouling impact risk to undersize the heat exchanger. This helps to remove some of the concerns expressed by 
scholars about the use of computer based optimization for heat exchangers design [14],

provided that reliable fouling growth data are available from experiments.

This joint optimization approach appears to be effective especially when fouling related costs are of the same order of magnitude respect the capital investment and the energy expense for fluid pumping. In this case an optimal balance among the three competing cost items is to be sought. In fact, when maintenance costs are negligible the life cycle cost minimization reduces to a design balancing capital investment and pressure losses and there is no need to concern about maintenance schedule. On the contrary, when fouling costs are dominant respect capital investment and pumping costs, then the equipment architecture does not affect the life cycle cost, which can be minimized by optimizing the cleaning schedule only or by pursuing a fouling free heat exchanger operating above the fouling threshold so that no cleaning is needed.

Therefore, we aim at cases where heat exchanger cost and maintenance cost are both high, i.e. in cases of single large sized units, or when they are both low, as happens when many small sized units are installed in the same process plant. In such cases a joint optimization approach minimizing the life cycle cost can determine significant economic savings.

The paper is organized as follows. At first a brief discussion of heat transfer surfaces fouling is carried out with reference to its impact on the exchanger performances and the cleaning process. Then the proposed optimization method is described. Finally, an application example is provided to show the capability of the method. The method has been developed with specific reference to shell and tube heat exchangers owing to their widespread diffusion. 


\section{HEAT EXCHANGERS FOULING}

During heat exchangers operations a progressive accumulation of fouling deposits occurs on both sides of the heat exchanging surfaces. This determines the gradual build up of an additional heat transfer resistance that reduces the overall heat transfer coefficient $\mathrm{U}$ and lowers the heat flow between hot and cold fluids. The overall heat transfer coefficient can be, in fact, expressed as

$$
1 / U=\frac{1}{\alpha_{s}}+R_{f_{o}}+\frac{D_{t} \ln \left(D_{t} / D_{t_{i}}\right)}{2 \lambda_{w}}+\frac{D_{t}}{D_{t_{i}}}\left(R_{f_{i}}+\frac{1}{\alpha_{t}}\right)
$$

where $R_{f o}$ and $R_{f i}$ are the shell side and the tube side fouling resistances respectively $\left(\mathrm{m}^{2}\right.$ $\mathrm{K} / \mathrm{W}), \alpha_{t}$ and $\alpha_{s}\left(\mathrm{~W} / \mathrm{m}^{2} \mathrm{~K}\right)$ are the tube side and shell side convective heat transfer coefficient respectively. $D_{t}$ and $D_{t i}$ are the tubes external and internal diameter (m), and $\lambda_{w}$ is the thermal conductivity of tube walls $(\mathrm{W} / \mathrm{m} \mathrm{K})$. The fouling phenomenon depends on several physical and operational parameters, namely the chemical nature of the fluids, the stream temperature, the surface roughness, the particulate load and foulant concentration in the fluid, the cristallization reactions constants, and the stream velocity, to name the most influent ones. Only a few of such parameters are under control of the designer. Obviously, as both shell and tube side fouling resistances increase through the time, the fouling phenomenon is time dependent. Furthermore, a pressure drop increase is observed due to reduction of flow pass area and a growth of the surface roughness [39-43].

While the discussion of fouling phenomena is beyond the scope of this paper the interested reader can consult a large number of literature works on this subject [44-51]. 
Whichever the fouling process, the growth of the fouling film through time can be expressed by

$$
\frac{d R_{f}}{d t}=\varphi_{d}-\varphi_{r}
$$

where $\phi_{d}$ is the fouling deposit growth rate and $\phi_{r}$ is the rate of deposit removal by the flow. The overall fouling layer growth law is very difficult to predict especially when it is time dependent. Generally, when deposits are brittle and the removal rate is proportional to the fouling layer thickness, the fouling film growth law is linear with time. In other cases the deposit rate decreases with time and the growth law is asymptotic.

An example of the progressive decay of the overall heat transfer coefficient $(U)$ from its initial value $U_{\text {clean }}$ is shown in Figure 1 according to different fouling mechanisms.

According to Ludwig [52], in case of asymptotic fouling, the fouling resistance can be obtained integrating equation (2) thus obtaining the following law of fouling resistance growth (also known as Kern and Seaton correlation)

$$
R_{f}=R_{f}^{*}\left(1-e^{-\beta t}\right)
$$

where $R_{f}^{*}$ is an asymptotic fouling resistance value which is related to the fluid velocity $\mathrm{v}$, the tube diameter $D_{t}$ and to the kind of foulant, while $\beta$ is the reciprocal of the fouling phenomenon time constant. Sample empirical correlations used for $R_{f}^{*_{f}}$ estimation for typical fluids are the following as given by Hewitt [2], 
$R_{f}^{*}=\frac{0.101}{v^{1.33} D_{t}^{0.23}} \quad$ Calcium carbonate on surface at constant temperature

$R_{f}^{*}=\frac{0.55}{v^{2}} \quad$ Oil deposit at constant heat flux

$R_{f}^{*}=\frac{0.015}{v^{1.2}} \quad$ Sand deposit from water at constant heat flux

In equation (3) parameter $\beta$, which is representative of the instantaneous fouling rate, is usually experimentally determined. In fact, it depends fom all the factors influencing the fouling process and is hard to estimate analytically. However, a major influencing parameter is the flow velocity. For instance, fouling rate is seen to vary as velocity to a power ranging from -0.35 to $-0.66[53,54]$, while other scholars report more complex relationships [55].

In this work, for sake of generality, we assume that the dependence of $\beta$ from flow velocity is represented by the following parametric equation,

$$
\beta=\beta_{0}\left(\frac{v}{v_{o}}\right)^{k}
$$

where $\beta_{0}$ is a known value at the arbitrary reference flow velocity $v_{0}$, while $\beta$ is the actual value at the flow velocity $v$.

This simplified formulation is highly flexible as many different $\beta$ trends corresponding to various fouling models can be easily accomodated by changing the value of exponent $k$. In fact, when $\mathrm{k}=0 \beta$ is constant, while when $\mathrm{k}= \pm 1 \beta$ changes linearly with flow velocity, and when $\mathrm{k}>1$ or $<1$ one has more or less than linear variations with velocity, where the sign of $\mathrm{k}$ defines the increasing or decreasing trend. 


\section{Moreover, in a suitably narrow interval around $v_{0}$ it is practically exact. Finally, given}

that the fouling rate depends on the flow regime (laminar or turbulent) one can choose different couples of $\beta_{0}$ and $\mathrm{k}$ values according to whether one is above or below a predetermined threshold velocity value $v_{0}$.

At the beginning of heat exchanger's operating life the heat transfer surfaces are clean and the overall heat transfer coefficient $U_{\text {clean }}$ is thus the sum of convective coefficients, tube and shell-side, and the reciprocal of the thermal resistance of tube wall. Then the fouling resistances are gradually added and progressively increase as the fouling layer build up, until the accumulated fouling film eventually determines an excessive heat transfer resistance and a cleaning operation is required to bring back the equipment to its original condition. Figure 2 shows the trend of gradual decay of $U$ and its periodical restoration for two different values of the allowable fouling resistance. By setting a threshold level for the maximum tolerated fouling resistance (i.e. the allowable fouling resistance $R_{f a l l}$, and knowing the trend of fouling resistance growth over time, it is thus possible to determine the timing of the cleaning operations. Under the asymptotic fouling hypothesis this corresponds to knowing the values of $\beta$ and $R_{f}^{*}$ and triggering the cleaning when $R_{f}$ computed by equation (3) becomes equal to $R_{f a l l}$. However, the choice of $R_{f \text { all }}$ value implies a trade off decision. In fact, referring to Figure 2 it can be observed that if the allowable fouling resistance is set to a small value, frequent maintenance stops are needed for cleaning. In this case, since the minimum value of $U$ is not much lower than $U_{\text {clean }}$, only a small oversizing of the exchanger results, thus limiting the extra surface and the additional investment cost. On the contrary, if the value of maximum fouling resistance is high, the maintenance stops would be less frequent reducing the cleaning cost, but a higher extra surface area will be needed to allow for the lower minimum value of $U$. In practice, given the heat duty 
specification, the heat transfer area is determined by assuming a value for the minimum allowable heat transfer coefficient in dirty operating conditions $U_{\text {dirt }}$. The lower the $U_{\text {dirt }}$ value is specified, the higher the oversizing of the heat exchanger results, but the lower the cleaning expenses. Conversely, if a high value of $U_{\text {dirt }}$ is assumed, a small oversizing results but more frequent cleaning operations will be required, thus asking for a trade off analysis. However, this trade off holds under the assumption that oversizing the heat exchanger means simply an extension of the heat transfer area without increasing the fluid flow cross section (i.e. by increasing, for instance, the tube length while maintaining the same bundle geometry and shell diameter). When, conversely, the oversizing of a heat exchanger brings lower fluid velocities owing to larger cross sections, this would accelerate fouling problems [56]. Then a larger oversizing of a heat exchanger is not necessarily associated to lower cleaning costs and the increased rate of fouling associated with lower flow velocities reduces the benefit afforded by the extra area.

To ensure the effectiveness of the equipment for an acceptable working period, designers must therefore necessarily overdesign the heat transfer surface, increasing the investment cost. This also asks for throttling the mass flow during the initial period of operating life when exchange surfaces are still clean and the transfer coefficient is high. Generally, an oversizing from $25 \%$ up to $50 \%$ respect the total surface area required in clean conditions is commonplace $[57,58]$. Often, probabilistic design methods are also employed to account for hardly predictable fouling effects [59-61].

However, an attempt to limit fouling by acting on the flow velocity can also be pursued. In fact, as already pointed out, the deposition rate is influenced by the stream velocity, and an increase of stream velocity can be beneficial from this point of view as the higher the fluids velocity, the lower the tendency to foul, even if an increase of pressure losses occurs. This also determines a trade off situation. 
The restoration of initial heat transfer conditions is made resorting to chemical or mechanical cleaning operations [62-65]. This often requires to put the equipment off line and determines additional costs related to unavailability and operational problems.

Usually, mechanical cleaning is less expensive than the chemical one, but when a strong mechanical action is required to remove deposits, even the mechanical cleaning methods needs the exchanger to be put off-line. Generally, a $30^{\circ}$ tube layout is more efficient from a thermal point of view but it doesn't allow a mechanical cleaning. On the contrary, $45^{\circ}$ or $90^{\circ}$ tube layouts, with or without clean lines, are suitable to mechanical cleaning but they are thermally less efficient. Moreover, the feasible kind of cleaning is related to the ratio of shell internal diameter to tubes outside diameter. Table 1 (from [2]) shows allowed shell-tube diameter combinations for mechanical cleaning.

Overall, setting a design value for $U_{\text {dirt }}$ determines a trade off between capital investment and cleaning costs, while setting a flow velocity impacts the trade off between capital investment, maintenance schedule and pumping costs. Moreover, the exchanger constructive arrangement determines the allowed cleaning method, thus further affecting the maintenance costs. Therefore, exchanger design and maintenance scheduling problems are strictly interrelated.

\section{PROPOSED APPROACH}

The proposed procedure for optimal heat exchanger design includes the following steps.

- Estimation of the exchanger heat transfer area based on the required duty and other design specification assuming a set of values for design variables including a maximum allowable fouling resistance $R_{\text {fall }}$; 
- evaluation of the capital investment, operating costs, and the objective function;

- utilization of the optimisation algorithm to select a new set of values for the design parameters;

- iteration of the previous steps until a minimum of the objective function is found.

The entire process is schematised in Figure 3. At present the procedure excludes heat transfer with phase change.

Design specification indicate the heat duty of the exchanger, and are set by imposing five of the following six parameters: the mass flow rates of the two fluids, as well as the inlet and outlet temperatures of the fluids shell-side $\mathrm{T}_{\mathrm{is}}, \mathrm{T}_{\mathrm{os}}$, and tube-side, $\mathrm{T}_{\mathrm{it}}, \mathrm{T}_{\mathrm{ot}}$. The remaining parameter being determined by an energy balance.

A set of thermo physical properties, process data and fixed characteristics of the equipment (i.e. heat exchanger TEMA type) are assigned by the designer. Starting from the input data, a random starting value is given to a set of independent design variables (VIP). The VIP number and meaning depends on the equations used to size the equipment. In this work the Bell-Delaware method $[2,66]$ has been used and the selected VIP are the inside shell diameter $D_{s}(\mathrm{~m})$, the tube outside diameter $D_{t}(\mathrm{~m})$, the central baffle spacing $L_{b c}(\mathrm{~m})$, the extremal baffle spacings $L_{b i}$ and $L_{b o}$, the pitch ratio $L_{p t R a t i o}$, the baffle cut $B_{c}$, the sealing strips number $N_{s s}$, the tube layout angle $\theta_{t p}$ and the tube pass number $N_{t p}$. A further independent variable is the maximum allowable fouling resistance $R_{\text {fall }}$. The other heat exchanger's characteristics (i.e. the dependent design variables, VDP) are then directly computed from the VIP. Using empirical rules of thumbs it is possible to determine the tubes number $N_{t}$, whereas using Bell-Delaware's design equations it is possible to evaluate all the others geometrical and fluid dynamical equipment characteristic. Once the VDP are computed from the VIP the overall heat transfer coefficient $(U)$ is estimated. This allows to determine the total heat exchanger's 
tubes length $L_{t t}(\mathrm{~m})$, the surface area $(\mathrm{S})$ and the baffles number $N_{b}$ (as an integer

multiple of $L_{b c}$ at least equal to the calculated $\left.L_{t t}\right)$.

The computed values of flow velocities and the constructive details of the exchanger structure are then used, resorting to Eqs. 3-7, to predict the time interval ( $\left.\mathrm{T}_{\text {clean }}\right)$ when the limit fouling resistance $R_{\text {fall }}$ is reached and cleaning is to be performed. Then, computation of the objective function follows.

Here we assume that the objective function to be minimized is the total life cycle cost $\left(\mathrm{C}_{\mathrm{tot}}\right)$ which is a sum of the capital investment, and the present worth of the pumping costs for overcoming friction losses and fouling related costs occurring over the equipment life.

Fouling related costs may include the following items [19, 33, 67].

a) Cleaning cost, i.e. the unit cost of each cleaning operation $C_{\text {clean }}(€)$. Cleaning of heat exchangers involves labour costs and capital expenditures for special equipment (tools, cranes etc.) [19].

b) Additional energy consumption in auxiliary heaters or coolers during exchanger cleaning if the exchanger is bypassed and the process unit is not shut down $\left(\mathrm{C}_{\mathrm{AUX}}\right)$. This cost is dependent on the cleaning downtime and can be included in the value of the cleaning operation cost.

c) Additional energy consumption in auxiliary heaters or coolers to compensate for progressive effectiveness drop in the exchanger, including any additional utilities consumption such as increased atomization steam in fuel oil injectors owing to increased fuel consumption, $\mathrm{C}_{\mathrm{E}}(€ / \mathrm{yr})$. Opportunity cost of lost production owing to reduction in throughput caused by fouling can be included in this item as is the extra maintenance costs of process equipment caused by fouling-related effects, such as replacement of furnace tubes due to prolonged operation at high temperatures. This cost can be computed over the interval between cleanings by integrating its instantaneous time-varying value $\mathrm{C}_{\mathrm{E}}(\mathrm{t})$. 
Miscellaneous costs $\left(\mathrm{C}_{\mathrm{M}}\right)$ such as managing the cleaning program, shutdown and startup of the process unit, opportunity cost of lost production during plant shutdown in the cleaning downtime, maintenance of cleaning equipment. This cost item can be included as well in the value of the cleaning operation cost.

All of the above cost items are strictly application-dependent and influenced by the economic scenario, so that a single reference value of general applicability can not be defined. $C_{\text {clean }}$ is dependent on the allowable kind of cleaning (mechanical or chemical). In case of mechanical cleaning $C_{\text {clean }}$ is the daily cleaning cost times the duration of the cleaning operation. The latter is usually a function of fouling deposit type and thickness and, therefore, depends on the time between cleanings as well as from the utilized cleaning equipment and workforce. Modern mechanical cleaning equipment allows a rapid cleaning as extensively described by Putman [68], Saxon and Putnam [65], Howell e Saxon [69]. Hydraulic cleaning resorting to high pressure lances is a proven technology. A tube cleaning velocity from 0.1 to $1.5 \mathrm{~m} / \mathrm{s}$ can be achieved with high pressure cleaning lances, and equipment allowing simultaneous cleaning of multiple tubes are available. Manufacturers reports cleaning speeds in the range of 80 to 750 tubes per hour. In that case a $4 \mathrm{~m}$ long tube could be cleaned in $4 \mathrm{~s}$ and a bundle made of 1000 tubes could be cleaned in a three to four hours considering the dead time to reposition the cleaning equipment. Saxon and Putman [65] report that a normal crew can clean 5000 tubes during a 12-hour shift, and that cleaning speed for a 20 -ft long severely fouled or blocked tube is 30 to $90 \mathrm{~s}$. Even self propelled bundle extractors and lifters to drive the extracted bundle to the cleaning bay are available to be operated by a single technician, and have capacities even in excess of $30 \mathrm{t}$.

In case of chemical cleaning $C_{c l e a n}$ includes the antifoulant cost and is often expressed as a function of the antifoulant consumption rate when on line cleaning is carried out. Chemical cleaning is often considered more costly than mechanical cleaning because 
additional circuitry involving pumps and tanks may be necessary, chemicals have to be purchased, and the cleaning process may produce an effluent that will require treatment before disposal [19]. However, chemical cleaning is compatible with nearly all exchangers internal configurations.

Casado [67] indicates a specific cleaning cost of 677 \$day and a cleaning downtime of 6 days. Smalili et al. [33] consider a value of $4000 £ /$ cleaning which is consistent with Casado data, while Markowski and Urbaniec [29] assume about 2500 \$/cleaning. However, all of the cited cases apply to large sized multiMW exchangers. Furthermore, Casado [67] reports, in 1980 dollars, a specific antifoulant cost of $7.3 \$ /(1000 \mathrm{lb})$ (1000 $\mathrm{ft}^{2}$ ) to be used at a typical concentration of $5 \mathrm{ppm}$.

From the above discussion a general expression of the total cost function can be expressed as

$$
C_{\text {tot }}=C_{I}+\sum_{i=1}^{N_{y r}} \frac{C_{e s}(1+f)^{i}}{(1+s)^{i}}+\sum_{i=1}^{N_{y r}} \frac{N_{\text {clean }}\left[\left(C_{\text {clean }, i}+C_{A U X, i}+C_{M, i}\right)+\int_{0}^{T_{\text {clean }}} C_{E, i}(t) d t\right]}{(1+s)^{i}}+\sum_{j=1}^{v} \alpha_{j} P_{j} C_{\text {fitt }}
$$

where $\mathrm{C}_{\mathrm{I}}$ is the capital investment $(€), C_{e s}$ is the annual operating cost due to pumping power caused by fluid friction losses (€/yr), $f$ is the energy cost inflation rate (\%/yr), $s$ is the interest rate (\%/yr), $N y r$ is the equipment life (yr), $N_{\text {clean }}=1 / \mathrm{T}_{\text {clean }}$ is the annual cleanings number $(1 / y r)$, The last term is an optional penalty function term which penalizes the cost of solutions violating one or more operating constraint imposed by user; $a_{j}$ is a binary activation index for the $j$-th constraint (imposed by user: 0 if the constraint is omitted, 1 if it is considered), $P_{j}$ is a binary violation index ( 0 if constraint is not violated, 1 otherwise), and $C_{\text {fitt }}$ is a fictitious cost set at a very high value that lead to the rejection of solutions not satisfying one or more constraint. The total cost function is thus completely determined by specifying the constructive details of the heat exchanger, the allowable fouling resistance and the economic scenario parameters. 
The genetic optimisation algorithm (GA), based on the value of the objective function, updates the trial values of the optimisation variables (VIP) which are then passed to the design routine to define a new architecture of the heat exchanger. The process is iterated until a minimum of the objective function is found or a prescribed convergence criterion is met, as shown in the flow diagram of Figure 3.

The GA is allowed to freely select the decision variables values within the set of values recommended by Hewitt [2] as a good pratice for heat exchangers construction. While mechanical cleaning is not allowed below $D_{t}=14 \mathrm{~mm}$, as already pointed out, it should be also noted that some combinations of the proposed decision variables may be an obstacle to cleaning (e.g. triangular layout of the bundle in case of mechanical cleaning). In this case the user can impose further constraint to the GA in order to avoid any undesired configuration.

Further details of the adopted genetic algorithm for the optimization process are given elsewhere [13].

It should be pointed out that the approach proposed in this work is centered on the trial assignment by the optimization algorithm of the allowable fouling resistance as an independent design variable, and on the computation of the cleaning frequency as dictated by the specified fouling resistance and the geometrical characteristic of the exchanger's through the resulting fluids velocities, as shown by equations 3 to 7 . Knowing the fouling mechanism it is, in fact, possible to determine the time dependence of fouling resistance as influenced by the constructive features of the equipment. Once the fouling resistance growth law for the actual heat exchanger and fluids is known, to set a threshold value for the fouling resistance is equal to set a service interval. In case a change in the equipment architecture during the optimization process determines a change in the fluid flow velocity, then its impact on the fouling rate is accounted for by 
Equation (7) which allows, through Equation (3), to update the estimate of the cleaning interval.

The proposed approach thus suggests to entrust the genetic algorithm with the autonomous choice of the optimal allowable fouling resistance, once the asymptotic decrease law of the overall heat transfer coefficient is known (Figure 1). In this manner the value to be assigned to this critical parameter is managed within the entire optimization procedure instead of being left to a trial and error approach or to the designer's arbitrary choice. The selected allowable fouling resistance determines, in fact, the extra heat transfer surface requirements and the cleaning frequency, thus setting the trade-off between capital investment and operating expenses. The resulting time schedule of maintenance cleaning is also the optimal schedule for minimum life cycle cost of the exchanger being designed. The reliability of the adopted fouling growth rate law is, therefore, critical, to the success of the method.

As a concluding remark it should be pointed out that the proposed joint optimization method is suitable especially in cases when fouling related costs are of the same order of magnitude respect the capital investment and the energy expense for fluid pumping. When maintenance costs are negligible the GA focuses on determining a heat exchanger architecture which minimizes the sum of capital investment and present worth of life cycle pumping energy consumption, irrespective of the cleaning schedule. When, on the contrary, fouling costs are dominant respect capital investment and pumping costs, then the GA merely tries to optimize the cleaning schedule without positively affecting the exchanger design, or even selects design parameters so that cleaning is never performed, i.e by selecting fluid velocities above the fouling threshold or by assuming the asymptotic fouling resistance as a design parameter. In such cases the use of the proposed design methodology is not appropriate. 


\section{CASE STUDY}

In order to test the effectiveness of the proposed approach a case study is presented here. The case study is based on the process specifications and streams data taken from a textbook heat exchanger sizing example from Kern [70]. The considered equipment exchanges heat between distilled water and raw water streams. The process data are shown in Tables 2 and 3. In Kern's original formulation a minimal tube-side velocity higher than $1.8 \mathrm{~m} / \mathrm{s}$ was imposed to prevent fouling. Here this constraint has been removed as the actual fouling resistance determined by fluid nature and velocity is considered. Moreover, no attempt will be made to compare the results of this model equipment sizing with the sizing approach of Kern in that in the original example no data were provided to determine the kind of fouling phenomenon which was considered.

The design optimization procedure was implemented on a personal computer resorting to the Genetic Algorithm toolbox of the scientific computing environment MATLAB. The heat exchanger was sized using the Bell-Delaware method and investment cost updated to 2007 values, was estimated adopting, for simplicity, the Hall approach [15] instead of a more accurate one [17]. Total cost was evaluated over a working period of five years $(40000 \mathrm{~h})$.

The mechanical and chemical cleaning cost was assumed as $250 € /$ cleaning and 500 $€ /$ cleaning respectively, the exchanger operated $8000 \mathrm{~h} / \mathrm{yr}$, the fuel cost inflation rate was neglected and the discount rate was set at $\mathrm{s}=10 \% / \mathrm{yr}$. Electric energy cost was $\mathrm{C}_{\mathrm{kWh}}$ $=0.12 € / \mathrm{kWh}$, and the pump efficiency was set as 0.75 . The value of the cleaning cost has been assumed considering the small size of the examined exchanger, wich has a duty of about $410 \mathrm{~kW}$ and a bundle composed of a few hundredts tubes. According to the preceding discussion on cleaning costs, it is likely that it could be cleaned in about half a work day by a team of no more that two operators justifying the above assump- 
tion. However, a sensitivity analysis on cleaning cost has also been carried out as shown

in the following. We also assumed that given the small size, and corresponding small capital investment of the equipment, a stand-by unit was available to bypass the flow without shutting down the process equipment, thus avoiding any cost related to process interruption $\left(\mathrm{C}_{\mathrm{AUX}}=0\right)$. Moreover, as we focus on cleaning operation only, the values of $\mathrm{C}_{\mathrm{M}}$ and $\mathrm{C}_{\mathrm{E}}$ were set to zero.

To compute the $\beta$ values the following assumptions were made; shell side $\beta_{0}=0.001$ day $^{-1}, v_{0}=0.5 \mathrm{~m} / \mathrm{s}, \mathrm{k}=-0.66$; tube side $\beta_{0}=0.0008 \mathrm{day}^{-1}, v_{0}=1 \mathrm{~m} / \mathrm{s}, \mathrm{k}=-0.66$. This gave the $\beta$ vs flow velocity trends shown in Figure 4.

Moreover, the following additional constraints were imposed to shell and tube side velocities $v_{\mathrm{s}}$ and $v_{\mathrm{t}}$, as well as to the shell length-to-diameter ratio and the extra surface, to ensure that the genetic algorithm converged to a technically feasible geometrical configuration of the equipment, namely

$$
\begin{aligned}
& 0.5<v_{\mathrm{t}}<4 \mathrm{~m} / \mathrm{s} \\
& 0.2<v_{\mathrm{s}}<1.5 \mathrm{~m} / \mathrm{s} \\
& 3<L / D_{s}<15
\end{aligned}
$$

The main characteristics of the resulting heat exchanger design as obtained from the optimization procedure proposed in this work are shown in Table 4 (column labeled “Joint Optimization”). For sake of comparison, in Table 4, TGA1, TGA2, TGA3 columns represent, instead, exchangers resulting from a traditional design optimization procedure carried out by a genetic algorithm similar to that discussed by Caputo et al. [13]. In those cases the heat exchanger architecture has been thus optimized neglecting the maintenance cost, with the aim of minimizing an objective function represented merely by the capital investment and the present value of the life cycle pumping energy cost. An allowable fouling resistance of respectively $0.91 \times 10^{-4}, 1.81 \times 10^{-4}, 3.62 \times 10^{-4}$ $\left[\mathrm{m}^{2} \mathrm{~K} / \mathrm{W}\right]$ was arbitrarily chosen by the designer as would happen in practice to 
properly oversize the equipment. The resulting maintenance schedule determined the

additional maintenance cost which was added to the former costs to estimate the overall cost. In the "Joint Optimization" column, instead, the genetic algorithm minimized an overall cost function sum of capital investment and present value of life cycle pumping energy cost and maintenance costs as proposed in this work. In this case the algorithm autonomously determined an "optimal" allowable fouling resistance value of $1.61 \times 10^{-4}$ $\left[\mathrm{m}^{2} \mathrm{~K} / \mathrm{W}\right]$. Finally, for sake of further comparison, an additional column labeled "Hybrid TGA" has been included in Table 4. This column represent a design obtained through the traditional genetic algorithm optimization approach (i.e. neglecting the maintenance cost in the objective function) but assuming as the designer-imposed allowable fouling resistance the same optimal value of $1.61 \times 10^{-4}\left[\mathrm{~m}^{2} \mathrm{~K} / \mathrm{W}\right]$ obtained through the joint optimization procedure.

Once the sizing algorithm in the optimization procedures has finalized the constructive details of the exchanger, the tubes diameter and flow velocity are determined and the asymptotic fouling resistance can be calculated thus allowing to determine the fouling growth curve and the time interval required to reach the imposed (TGA1, TGA2, TGA3, Hybrid TGA) or the self-determined (Joint Optimization) allowable fouling resistance. This allows to compute the number of cleaning operations, maintenance cost and the overall cost of the heat exchangers as shown in the Table.

A minimum cost value of about $19936 €$ has been obtained by the proposed "joint optimization" approach. It interesting to note that when comparing the heat exchanger design obtained by the "joint optimization" with that of the "hybrid" approach (i.e. having the same "optimal" allowable fouling resistance value) a different design results confirming the effectiveness of the "joint optimization" approach. In particular, when maintenance costs are neglected, the "hybrid" approach gives a lower total cost exchanger respect the "joint optimization" one (17900€ vs $18988 €)$, but when the 
maintenance cost is factored in the situation is reversed (28135 $€$ vs $19936 €)$ and the "joint approach" shows to be superior.

It is worth noting that even if all of the other exchangers (TGA1, TGA2, TGA3, Hybrid TGA) have been obtained by minimizing a total cost function including capital investment and energy cost, the fact that the allowable fouling resistance value was arbitrarily set by the designer, as happens in practice, determined higher overall costs than the ones incurred when even the allowable fouling resistance is treated as an independent variable to be optimized. Overall, respect the best performing solution, all other "optimized" solutions deteminad a cost increase of $11 \%$ to $30 \%$ which is significant. This confirms that the arbitrary selection of a design value for the allowable fouling resistance may significantly impact the life cycle cost of an exchanger leading to poor economic performances, and that a computer based "joint optimization" approach can be a viable design alternative.

Table 4 also shows the resulting heat exchange area (S) in comparison with the theoretical heat transfer area $\left(S_{\text {clean }}\right)$ required to satisfy the duty specifications had the fouling phenomenon been negligible. A fouling-related percent increase of the heat transfer area $\left(\mathrm{S}_{\mathrm{extra}}\right)$ thus follows. It can be observed that the optimal design value of the maximum fouling resistance implied an extra surface of $27 \%$ respect the value obtainable neglecting fouling phenomena, consistent with extra surface values suggested in the literature (ranging up to about $35 \%$ ).

In case of the optimal "joint optimization" exchanger a total of 5 cleaning operations are performed during the life cycle of $40000 \mathrm{~h}$ and the optimal maintenance interval is about 6956 hours, i.e about once per year. The resulting trend of the overall heat transfer coefficients and the corresponding maintenance schedules are shown in Figures 5, 6, 7 
for the "Joint Optimization" exchanger as well as the TGA2, and the "hybrid TGA" designs for sake of comparison.

Table 5 shows the influence of fouling rate obtained by changing the value of parameter $k$ in Equation (7). Finally, Table 6 shows the results of a sensistivity analysis on the cleaning cost. It can be oserved that when maintenance cost increase the GA can change the heat exchanger architecture so that maintenance is never carried out (i.e the allowed fouling resistance is set at the asymptotic value).

\section{CONCLUSIONS}

In the paper a new design approach has been developed for finding the optimal shell and tube heat exchanger configuration including the optimization of its cleaning schedule. The optimization is based on the minimization of a total cost function including capital investment and operational expenses connected to fluid moving and the equipment periodical cleaning or any other fouling related expenditure. This model is based on considering the maximum fouling resistance as one of the design parameters to be optimized, provided that a reliable fouling growth rate estimation correlation is available. This automatically solves the trade off implied by the choice of surface area, cleaning schedule and flow velocities. The model is also able to evaluate the kind of cleaning methods allowable for the designed heat exchanger. The proposed model is a useful addition to the existing design optimization methods which neglect fouling phenomena and periodical cleaning issues, and is more effective that traditional cleaning schedule optimization methods which are applied to an exchanger of predefined configuration. In this method, in fact, the problem of finding a geometric configuration and cleaning schedule of the equipment is solved simultaneously 
considering the impact that the equipment architecture has on the fouling process and the resulting cleaning requirements. The model is expected to be effective especially when fouling related costs are of the same order of magnitude respect the capital investment and pumping energy expenditure. In fact, in this case the sizing problem and the maintenance scheduling problem become interconnected from a cost optimization perspective. This is likely to occur in case of large size and high cost exchangers or in case of many smaller size units installed in the same plant, where small unit savings make great overall savings. Overall, when cleaning costs become dominant the contribution of design related costs becomes irrelevant. When, instead, equipment cost are dominant then maintenance scheduling becomes irrelevant. In both cases the two problems can be solved separately. Furthermore, when low cost exchangers are utilized a stand by unit can be easily afforded making the optimization of the cleaning schedule less relevant. In all other cases the design and maintenance problems are strictly interdependent and a joint optimization approach is a valuable alternative.

As a future research it is planned to account for the effects of fouling on fluid flow pressure drop and to include several different fouling growth laws to make the model of general applicability. Furthermore, the fouling rate will be made dependent on the local temperature within the heat exchanger. This will require to couple the exchanger sizing module with a detailed thermal performance estimation model.

\section{REFERENCES}

[1] T.Kuppan, Heat exchanger design handbook, CRC Press, 2000.

[2] G.F.Hewitt (Ed.), Heat exchanger design handbook, Begell House, 1998.

[3] G.T. Polley, D.I. Wilson, B.L. Yeap, S.J. Pugh, Use of crude oil fouling threshold data in heat exchanger design, Applied Thermal Engineering, 22 (2002) 763-776.

[4] R.E. Putman, The economics of regular condenser maintenance, Corporate publication, Conco Consulting Corp. Verona, PA, USA. Available at the URL 
http://www.concosystems.com/Files/Articles/Return\%20on\%20Investment\%20Anal ysis \%20The\%20Economics\%20of\%20Regular\%20Condenser\%20Maintenance.pdf (accessed October 2010).

[5] B. Khalifeh Soltan, M. Saffar-Avval, E. Damargin, Minimizing capital and operating costs of shell and tube condensers using optimum baffle spacing, Applied Thermal Engineering 24 (2004) 2801-2810.

[6] A. Unuvar, S.Kargici, An approach for the optimum design of heat exchangers, International Journal of Energy Research (2004) 1379-1392.

[7] R. Selbas, O. Kizilkan, M. Reppich, A new design approach for shell and tube heat exchangers using genetic algorithms from economic point of view, Chemical Engineering and Processing 45 (2006) 268-275.

[8] M. Sena-Gonzalez, , J.M. Ponce-Ortega, A.J.Castro-Montoya, A.Jimenez-Gutierrez, Feasible design space for shell and tube heat exchangers using Bell-Delaware method, Industrial Engineering Chemical Research 46 (2007) 143-155.

[9] J.M. Ponce-Ortega, M. Sena-Gonzalez, A. Jimenez-Gutierrez, Use of genetic algorithm for the optimal design of shell-and-tube heat exchangers, Applied Thermal Engineering 29 (2009) 203-209.

[10] A.L.H. Costa, E.M. Queiroz, Design optimization of shell and tube heat exchangers, Applied Thermal Engineering, 28 (2008) 1798-1805.

[11] M.C. Tayal, Y. Fu, U.M. Diwekar, Optimal design of heat exchangers: A genetic algorithm framework, Industrial Engineering Chemical Research 38 (1999) 456-467.

[12] B.V. Babu, S.A. Munawar, Differential evolution strategies for optimum design of shell and tube heat exchangers, Chemical Engineering Science 62 (2007) 3720-3739.

[13] A.C. Caputo, M.P.Pelagagge, P.Salini, Heat exchangers design based on economic optimization, Applied Thermal Engineering 28 (2008) 1151-1159.

[14] K.J. Bell, On the pessimization of heat exchangers, Heat Transfer Engineering, 21 (2000) $1-2$.

[15] M. Taal, I. Bulatov, J. Klemes, P.Stehlik, Cost estimation and energy price forecast for economic evaluation of retrofit projects, Applied Thermal Engineering 23 (2003) 1819-1835. 
[16] A.C. Caputo, P.M. Pelagagge, P. Salini, Optimal cost-based design of shell and tube heat exchangers, Proc. $12^{\text {th }}$ Brazilian Congress on Thermal Engineering and Sciences ENCIT 2008, November 10-14 2008, Belo Horizonte, Brasil.

[17] A.C. Caputo, P.M. Pelagagge, P. Salini, A manufacturing-based cost model for shell and tube heat exchangers, Proc. 7th International Conference on Manufacturing Research (ICMR09), University of Warwick, UK, September 8-10, 2009.

[18] R.E. Putman, Timing cleanings to boost heat exchanger performance: Cutting costs, facilitating production, Chemical Processing 64 (2001) 39-41.

[19] J.U.R. Khan, S.M. Zubair, A risk-based performance analysis of plate-and-frame heat exchangers subject to fouling: Economics of heat exchanger cleaning, Heat Transfer Engineering 25 (2004) 87-100.

[20] B.R. O'Donnell, B.A. Barna, C.D. Gosling, Optimize heat exchanger cleaning schedules, Chemical Engineering Progress 97 (2001) 56-60.

[21] A.K. Sheikh, S.M. Zubair, M.U. Haq, M.O. Budair, Reliability-based maintenance strategies for heat exchangers subject to fouling, Journal of Energy Resources Technology, Transactions of the ASME, 118 (1996) 306-312.

[22] S.M. Zubair, A.K. Sheikh, M.O. Budair, M.A. Badar, A maintenance strategy for heat transfer equipment subject to fouling: A probabilistic approach, Journal of Heat Transfer 119 (1997) 575-580.

[23] S.M. Zubair, R.K. Shah, Fouling of plate-and-frame heat exchangers and cleaning strategies, International Journal of Heat Exchangers 5 (2004) 129-156.

[24] M.C. Georgiadis, L.G. Papageorgiou, Optimal energy and cleaning management in heat exchanger networks under fouling, Chemical Engineering Research and Design 78 (2000) 168-179.

[25] M.C. Georgiadis, L.G. Papageorgiou, S. Macchietto, Optimal cleaning policies in heat exchanger networks under rapid fouling, Industrial and Engineering Chemistry Research 39 (2000) 441-454.

[26] J.H. Lavaja, M.J. Bagajewicz, On a new MILP model for the planning of heatexchanger network cleaning, Industrial and Engineering Chemistry Research 43 (2004) 3924-3938. 
[27] Lavaja J. and M. Bagajewicz. A New MILP Model for the Planning of Heat Exchanger Network Cleaning. Part II: Throughput Loss Considerations. Industrial and Engineering Chemistry Research 44 (2005) 8045-8056.

[28] J.H. Lavaja, M.J. Bagajewicz, On a new MILP model for the planning of heatexchanger network cleaning. Part III: Multiperiod cleaning under uncertainty with financial risk management, Industrial and Engineering Chemistry Research 44 (2005) 8136-8146.

[29] M. Markowski, K. Urbaniec, Optimal cleaning schedule for heat exchangers in a heat exchanger network, Applied Thermal Engineering, 25 (2005) 1019-1032.

[30] S. Sanaye, B. Niroomand, Simulation of heat exchanger network (HEN) and planning the optimum cleaning schedule, Energy Conversion and Management 48 (2007) 1450-1461.

[31] F. Smaili, V.S. Vassiliadis, D.I. Wilson, Mitigation of fouling in refinery heat exchanger networks by optimal management of cleaning, Energy and Fuels 15 (2001) 1038-1056.

[32] F. Smaili, V.S. Vassiliadis, D.I. Wilson, Long-term scheduling of cleaning of heat exchanger networks: Comparison of outer approximation-based solutions with a backtracking threshold accepting algorithm, Chemical Engineering Research and Design 80 (2002) 561-578.

[33] F. Smaili, V.S. Vassiliadis, D.I. Wilson, Optimization of cleaning schedules in heat exchanger networks subject to fouling, Chemical Engineering Communications, 189 (2002) 1517-1549.

[34] P. Wildi-Tremblay, L. Gosselin, Minimizing shell and tube heat exchanger cost with genetic algorithms and considering maintenance, International Journal of Energy Research (2007) 867-885.

[35] D. Butterworth, Design of shell-and-tube heat exchangers when the fouling depends on local temperature and velocity, Applied Thermal Engineering, 22 (2002) 789-801.

[36] D.I. Wilson, G.T. Polley, S.J. Pugh, Mitigation of crude oil preheat train fouling by design, Heat Transfer Engineering, 23 (2002) 24-37.

[37] P.J. Fryer, P.J. Hobin, S.P. Mawer, Optimal design of a heat exchanger undergoing reaction fouling, Canadian Journal of Chemical Engineering 66 (1988) 558-562. 
[38] C.A. Branch, H. Müller-Steinhagen, Influence of scaling on the performance of shell-and-tube heat exchangers, Heat Transfer Engineering 12 (2) (1991) 36-45.

[39] T.R. Bott, Fouling of heat exchangers, Elsevier, 1995.

[40] R.W. Bryers, Fouling of heat exchanger surfaces, Engineering Foundation, 1983.

[41] B.A. Garrett-Price, S.A. Smith, R.L. Watts, J.G. Knudsen, Fouling of heat exchangers: Characteristics, costs, prevention, control, and removal”, Noyes Pub., 1985.

[42] H. Muller-Steinhagen, Heat exchanger fouling: Mitigation and cleaning techniques, Institution of Chemical Engineers, UK, 2000.

[43] H. Muller-Steinhagen, M.R. Malayeri, A.P. Watkinson, Recent advances in heat exchanger fouling research, mitigation, and cleaning techniques, Heat Transfer Engineering, 28 (2007) 173-176.

[44] S. Jun, V.M. Puri, Fouling models for heat exchangers in dairy processing: A review, Journal of Food Process Engineering 28 (2005) 1-34.

[45] A.K. Sheikh, S.M. Zubair, M. Younas, M.O. Budair, Statistical aspects of fouling processes, Proceedings of the Institution of Mechanical Engineers, Part E: Journal of Process Mechanical Engineering, 215 (2001) 331-354.

[46] M.R. Jafari Nasr, M. Majidi Givi, Modeling of crude oil fouling in preheat exchangers of refinery distillation units, Applied Thermal Engineering 26 (2006) 15721577.

[47] M.N. LeClercq-Perlat, M. Lalande, Review on the modeling of the removal of porous contaminants deposited on heat transfer surfaces, International Chemical Engineering 31 (1991) 74-93.

[48] S. McGurn, S. Thompson, Heat transfer models for boiler fouling monitoring, Transactions of the Institute of Measurement and Control 17 (1995) 212-222.

[49] M.G. Mwaba, M.R. Golriz, J. Gu, A semi-empirical correlation for crystallization fouling on heat exchange surfaces, Applied Thermal Engineering 26 (2006) 440-447.

[50] C. Riverol, V. Napolitano, Estimation of fouling in a plate heat exchanger through the application on neural networks, Journal of Chemical Technology and Biotechnology 80 (2005) 594-600. 
[51] H. Zabiri, V.R. Radhakrishnan, M. Ramasamy, N.M. Ramli, V. Do Thanh, C.S.

Wah, Development of heat exchanger fouling model and preventive maintenance diagnostic tool, Chemical Product and Process Modeling 2 (2007).

[52] E.E. Ludwig, ,Applied process design for chemical and petrochemical plants, vol.3, 3rd Ed., Gulf Publishing, 2001.

[53] M. Srinivasan, A.P. Watkinson, Fouling of some canadian crude oils, in P. Watkinson, H. Muller-Steinhagen, and M. Reza Malayeri, (Eds.), 2003 ECI Conference on Heat Exchanger Fouling and Cleaning: Fundamentals and Applications, Santa Fe, New Mexico, USA, paper 26, 192-199, 2004.

[54] F. Brahim, W. Augustin, M. Bohnet, Numerical simulation of the fouling on, structured heat transfer surfaces (Fouling), in P. Watkinson, H. Muller-Steinhagen, and M. Reza Malayeri, (Eds.), 2003 ECI Conference on Heat Exchanger Fouling and Cleaning: Fundamentals and Applications, Santa Fe, New Mexico, USA, paper 17, 121-129, 2004.

[55] B.L. Yeap, D.I. Wilson, G.T. Polley, S.J. Pugh, Retrofitting crude oil refinery heat exchanger networks to minimise fouling while maximising heat recovery, in P. Watkinson, H. Muller-Steinhagen, M. Reza Malayeri (Eds.), 2003 ECI Conference on Heat Exchanger Fouling and Cleaning: Fundamentals and Applications, Santa Fe, New Mexico, USA, paper 28, 211-218, 2004.

[56] E.M. Ishiyama, W.R. Paterson, D.I. Wilson, Thermo-hydraulic channelling in parallel heat exchangers subject to fouling, Chemical Engineering Science, 63 (2008) 3400-3410.

[57] B.C. Pak, E.A. Groll, J.E. Braun, Impact of fouling and cleaning on plate fin and spine fin heat exchanger performance, ASHRAE Transactions, 111 Part 1, art. no. OR-05-1-3 (2005) 496-504.

[58] H. Sanatgar, E.F.C. Somerscales, Account for fouling in heat exchanger design, Chemical Engineering Progress 87 (1991) 53-59.

[59] S.M. Zubair, A.K. Sheikh, M. Younas, M.O. Budair, A risk based heat exchanger analysis subject to fouling: Part I: Performance evaluation, Energy 25 (2000) 427443. 
[60] S.M. Zubair, A.K. Sheikh, M. Younas, M.O. Budair, A risk based heat exchanger analysis subject to fouling: Part II: Economics of heat exchangers cleaning, Energy 25 (2000) 445-461.

[61] S.M. Zubair, B.A. Qureshi, A probabilistic fouling and cost model for plate-andframe heat exchangers, International Journal of Energy Research 30 (2006) 1-17.

[62] N.A. Abdul-Latif, S.H.F. Al-Madfai, A.N. Ghanim, Removal of scale deposited on heat-transfer surfaces using chemical methods, Industrial and Engineering Chemistry Research 27 (1988) 1548-1551.

[63] W.W. Frenier, S.J. Barber, Choose the best heat exchanger cleaning method, Chemical Engineering Progress 94 (1998) 37-44.

[64] D.I. Wilson, Challenges in cleaning: Recent developments and future prospects, in P. Watkinson, H. Muller-Steinhagen, M. Reza Malayeri (Eds.), 2003 ECI Conference on Heat Exchanger Fouling and Cleaning: Fundamentals and Applications, Santa Fe, New Mexico, USA, paper 21, 148-157, 2004.

[65] G.E: Saxon, R.E. Putman, The practical application and innovation of cleaning technology for heat exchangers, in P. Watkinson, H. Muller-Steinhagen, M. Reza Malayeri (Eds.), 2003 ECI Conference on Heat Exchanger Fouling and Cleaning: Fundamentals and Applications, Santa Fe, New Mexico, USA, paper 28, 211-218, 2004.

[66] R.K. Shah, D.P. Sekulic, Fundamentals of heat exchanger design, Wiley, 2003.

[67] E. Casado, Model optimizes exchanger cleaning, Hydrocarbon Processing (1980) 71-76.

[68] R.E. Putman, Optimizing the cleaning of heat exchangers, Corporate publication, Conco Consulting Corp. Verona, PA, USA. Available at the URL http://www.concosystems.com/Files/Articles/Optimizing\%20the\%20Cleaning\%20of $\% 20$ Heat\%20Exchangers.pdf (accessed October 2010).

[69] A.G. Howell, G.E. Saxon Jr, Condenser tube fouling and failures: Causes and mitigation, Power Plant Chemistry, 7 (2005) 708-716.

[70] D.Q. Kern, Process heat transfer, McGraw-Hill, 1950. 


\section{Figures captions}

Figure 1 - Different kind of fouling trends (adapted from [33]).

Figure 2- Influence of allowed fouling resistance on cleaning policy.

Figure 3 - Flow chart of optimization procedure using GA and considering maintenance.

Figure 4 - Trend of $\beta$ vs flow velocity tubeside ( $\beta_{\mathrm{T}}$ curve) and shell side ( $\beta_{\mathrm{S}}$ curve).

Figure 5 - U trend through 5 years for the "Joint Optimization" exchanger.

Figure 6 - U trend through 5 years for the "TGA2" exchanger.

Figure 7 - U trend through 5 years for the "Hybrid TGA2" exchanger. 
Table 1. Allowed shell/tube sizes couplings (dotted area: recommended, dashed area: possible). Below $\mathrm{D}_{\mathrm{t}}=14 \mathrm{~mm}$ mechanical cleaning is not allowed).

\begin{tabular}{|c|c|c|c|c|c|c|c|}
\hline $\mathrm{D}_{\mathrm{t}} D_{s}$ & 100 & 200 & 300 & 500 & 700 & 1000 & 1500 \\
\hline 6 & & & & & & & \\
\hline 10 & & & & & & & \\
\hline 14 & & & & & & & \\
\hline 20 & & & & & & & \\
\hline 25 & & & & & & & \\
\hline 38 & & & & & & & \\
\hline 51 & & & & & & & \\
\hline
\end{tabular}


Table 2. Heat exchanger thermal characteristics

\begin{tabular}{ccc|ccc|ccc}
\hline Duty & {$[\mathrm{kW}]$} & 410 & $\mathrm{~F}_{\mathrm{t}}$ & {$[-]$} & 0.947 & $\mathrm{~F}_{\mathrm{t}}$ & {$[-]$} & 1 \\
\hline$\Delta \mathrm{TLM}$ & {$\left[{ }^{\circ} \mathrm{C}\right]$} & 6.35 & $\Delta \mathrm{Tm}$ & {$\left[{ }^{\circ} \mathrm{C}\right]$} & 6.01 & $\Delta \mathrm{Tm}$ & {$\left[{ }^{\circ} \mathrm{C}\right]$} & 6.35 \\
\hline & \multicolumn{4}{|c|}{ Two or more tube passes } & \multicolumn{2}{c}{ One countercurrent tube pass } \\
\hline
\end{tabular}


Table 3. Process Data

\begin{tabular}{lll|lll}
\hline \multicolumn{2}{l}{ Shell Side } & \multicolumn{4}{l}{ Tube Side } \\
\hline \multicolumn{4}{l}{ Distilled water } & \multicolumn{4}{l}{ Raw water } \\
\hline Inlet temperature $\mathrm{T}_{\mathrm{si}}$ & {$\left[{ }^{\circ} \mathrm{C}\right]$} & 33.889 & Inlet temperature $\mathrm{T}_{\mathrm{ti}}$ & {$\left[{ }^{\circ} \mathrm{C}\right]$} & 23.889 \\
\hline Outlet temperature $\mathrm{T}_{\mathrm{so}}$ & {$\left[{ }^{\circ} \mathrm{C}\right]$} & 29.444 & Outlet temperature $\mathrm{T}_{\mathrm{to}}$ & {$\left[{ }^{\circ} \mathrm{C}\right]$} & 26.667 \\
\hline Mass flow rate $\mathrm{M}_{\mathrm{s}}$ & {$[\mathrm{kg} / \mathrm{s}]$} & 22.050 & Mass flow rate $\mathrm{M}_{\mathrm{t}}$ & {$[\mathrm{kg} / \mathrm{s}]$} & 35.279 \\
\hline Fluid density $\rho_{\mathrm{s}}$ & {$\left[\mathrm{kg} / \mathrm{m}^{3}\right]$} & 995 & Fluid density $\rho_{\mathrm{t}}$ & {$\left[\mathrm{kg} / \mathrm{m}^{3}\right]$} & 995 \\
\hline Fluid conductivity $\lambda_{\mathrm{s}}$ & {$[\mathrm{W} / \mathrm{m} \mathrm{K}]$} & 0.615 & Fluid conductivity $\lambda_{\mathrm{t}}$ & {$[\mathrm{W} / \mathrm{m} \mathrm{K}]$} & 0.605 \\
\hline Fluid specific heat $\mathrm{C}_{\mathrm{ps}}$ & {$[\mathrm{J} / \mathrm{kg} \mathrm{K}]$} & 4184 & Fluid specific heat $\mathrm{C}_{\mathrm{pt}}$ & {$[\mathrm{J} / \mathrm{kg} \mathrm{K}]$} & 4184 \\
\hline Fluid viscosity $\eta_{\mathrm{s}}$ & {$[\mathrm{mPa} / \mathrm{s}]$} & 0.773 & Fluid viscosity $\eta_{\mathrm{t}}$ & {$[\mathrm{mPa} / \mathrm{s}]$} & 0.887 \\
\hline
\end{tabular}


Table 4. Proposed Heat exchanger optimized designs

\begin{tabular}{|c|c|c|c|c|c|c|c|}
\hline Parameter & & & TGA 1 & TGA 2 & TGA 3 & $\begin{array}{c}\text { Joint } \\
\text { Optimiz. }\end{array}$ & $\begin{array}{l}\text { Hybrid } \\
\text { TGA }\end{array}$ \\
\hline Shell diameter & $D_{s}$ & {$[\mathrm{~mm}]$} & 457.2 & 457.2 & 500.8 & 355.6 & 406.4 \\
\hline Baffle cut & $\mathrm{B}_{\mathrm{c}}$ & {$[\%]$} & 43 & 19 & 32 & 35 & 31 \\
\hline Number of baffles & $\mathrm{N}_{\mathrm{b}}$ & {$[-]$} & 4 & 3 & 7 & 14 & 4 \\
\hline Central baffle spacing & $\mathrm{L}_{\mathrm{bc}}$ & {$[\mathrm{mm}]$} & 457.2 & 457.2 & 500.8 & 355.6 & 406.4 \\
\hline Extremal baffles spacing & $\mathrm{L}_{\mathrm{bi}}, \mathrm{L}_{\mathrm{bo}}$ & {$[\mathrm{mm}]$} & 457.2 & 457.2 & 500.8 & 355.6 & 406.4 \\
\hline Pitch ratio & $\mathrm{L}_{\text {toRatio }}$ & [\%] & 1.32 & 1.37 & 1.31 & 1.27 & 1.50 \\
\hline Tubes ext. diameter & $\mathrm{D}_{\mathrm{t}}$ & {$[\mathrm{mm}]$} & 15.88 & 12.70 & 22.23 & 22.23 & 9.53 \\
\hline Tubes int. diameter & $\mathrm{D}_{\mathrm{ti}}$ & {$[\mathrm{mm}]$} & 14.10 & 10.92 & 20.45 & 20.45 & 8.10 \\
\hline Tubes pitch & $\mathrm{L}_{\mathrm{tp}}$ & {$[\mathrm{mm}]$} & 21.02 & 17.43 & 29.06 & 28.12 & 14.28 \\
\hline Tube layout angle & $\theta_{\mathrm{tp}}$ & [deg] & 30 & 30 & 30 & 45 & 30 \\
\hline Tube passes & $\mathrm{N}_{\mathrm{tp}}$ & {$[-]$} & 2 & 2 & 2 & 1 & 1 \\
\hline Tubes number & $\mathrm{N}_{\mathrm{tt}}$ & {$[-]$} & 371 & 548 & 229 & 107 & 681 \\
\hline Tubes length & $\mathrm{L}_{\mathrm{tt}}$ & {$[\mathrm{mm}]$} & 2311.0 & 1853.8 & 4031.4 & 5384 & 2057.0 \\
\hline Flow velocity (tube-side) & $v_{t}$ & {$[\mathrm{~m} / \mathrm{s}]$} & 1.225 & 1.381 & 0.943 & 1.009 & 1.010 \\
\hline Flow velocity (shell-side) & $\mathrm{v}_{\mathrm{S}}$ & {$[\mathrm{m} / \mathrm{s}]$} & 0.472 & 0.368 & 0.436 & 0.593 & 0.276 \\
\hline $\begin{array}{l}\text { Reynolds number (shell- } \\
\text { side) }\end{array}$ & $\operatorname{Re}_{\mathrm{s}}$ & {$[-]$} & 8884 & 6397 & 10876 & 17587 & 4957 \\
\hline Prandtl number (shell-side) & $\operatorname{Pr}_{\mathrm{s}}$ & {$[-]$} & 5.3 & 5.3 & 5.3 & 5.3 & 5.3 \\
\hline $\begin{array}{l}\text { Reynolds number (tube- } \\
\text { side) }\end{array}$ & $\mathrm{Re}_{\mathrm{t}}$ & {$[-]$} & 21472 & 18762 & 23983 & 25664 & 10175 \\
\hline Prandtl number (tube-side) & $\mathrm{Pr}_{\mathrm{t}}$ & {$[-]$} & 5.5 & 5.5 & 5.5 & 5.5 & 5.5 \\
\hline $\begin{array}{l}\text { Convective heat transfer } \\
\text { coefficient (shell-side) }\end{array}$ & $\alpha_{\mathrm{s}}$ & {$\left[\mathrm{W} / \mathrm{m}^{2} \mathrm{~K}\right]$} & 3054.2 & 4685.6 & 3199.2 & 4500.6 & 4588.9 \\
\hline $\begin{array}{l}\text { Convective heat transfer } \\
\text { coefficient (tube-side) }\end{array}$ & $\alpha_{t}$ & {$\left[\mathrm{~W} / \mathrm{m}^{2} \mathrm{~K}\right]$} & 5951.8 & 6896.2 & 4483.1 & 4732.8 & 5697.4 \\
\hline $\begin{array}{l}\text { Overall heat transfer coef- } \\
\text { ficient }\end{array}$ & $\mathrm{U}_{\text {dirt }}$ & {$\left[\mathrm{W} / \mathrm{m}^{2} \mathrm{~K}\right]$} & 1640.7 & 1767.6 & 1082.1 & 1620.0 & 1701.8 \\
\hline Actual heat exchange area & $\mathrm{S}$ & {$\left[\mathrm{m}^{2}\right]$} & 41.83 & 39.44 & 63.66 & 39.85 & 40.90 \\
\hline Basic heat exchange area & $\mathrm{S}_{\text {clean }}$ & {$\left[\mathrm{m}^{2}\right]$} & 35.24 & 26.06 & 37.86 & 29.17 & 27.39 \\
\hline $\begin{array}{l}\text { Additional heat exchange } \\
\text { area }\end{array}$ & $S_{\text {extra }}$ & {$[\%]$} & 16 & 34 & 41 & 27 & 33 \\
\hline $\begin{array}{l}\text { Pressure drop } \\
\text { (shell-side) }\end{array}$ & $\Delta \mathrm{p}_{\mathrm{s}}$ & {$[\mathrm{kPa}]$} & 3.33 & 4.66 & 4.16 & 18.42 & 5.52 \\
\hline $\begin{array}{l}\text { Pressure drop } \\
\text { (tube-side) }\end{array}$ & $\Delta \mathrm{p}_{\mathrm{t}}$ & {$[\mathrm{kPa}]$} & 7.55 & 10.24 & 5.08 & 3.57 & 4.32 \\
\hline Maintenance method & $2+2$ & & Chemical & Chemical & Chemical & Mechanical & Chemical \\
\hline Operating cost & $\mathrm{C}_{\mathrm{es}}$ & {$[€ / \mathrm{yr}]$} & 437.2 & 596.9 & 348.6 & 684.7 & 352.7 \\
\hline Allowed fouling resistance & $\mathrm{R}_{\mathrm{f} \text { allowable }}$ & {$\left[\mathrm{m}^{2} \mathrm{~K} / \mathrm{W}\right]$} & 0.000091 & 0.000181 & 0.000362 & 0.000161 & 0.000161 \\
\hline Cleaning interval & $\mathrm{T}_{\text {clean }}$ & {$[\mathrm{h}]$} & 2614 & 3385 & 10578 & 6956 & 1438 \\
\hline Overall cleanings number & $\mathrm{N}$ & {$[-]$} & 15 & 11 & 3 & 5 & 27 \\
\hline $\begin{array}{l}\text { Operating cost present } \\
\text { value }\end{array}$ & $\mathrm{C}_{\mathrm{es}, \mathrm{tot}}$ & [€] & 1657.3 & 2262.9 & 1321.5 & 2595.2 & 1337.1 \\
\hline $\begin{array}{l}\text { Cleaning cost present } \\
\text { value }\end{array}$ & $\mathrm{C}_{\text {clean,tot }}$ & [€] & 5686.2 & 4169.8 & 1137.2 & 947.7 & 10235.1 \\
\hline Capital investment & $\mathrm{C}_{\mathrm{I}}$ & {$[€]$} & 16715.0 & 16326.1 & 20083.2 & 16393.2 & 16563.6 \\
\hline Cost & $\mathrm{C}_{\mathrm{I}}+\mathrm{C}_{\mathrm{es}, \mathrm{tot}}$ & {$[€]$} & 18372.3 & 18588.9 & 21404.7 & 18988.4 & 17900.7 \\
\hline Total cost & $\begin{array}{l}\mathrm{C}_{\mathrm{I}}+\mathrm{C}_{\mathrm{es}, \text { tot }}+ \\
\mathrm{C}_{\text {clean,tot }} \\
\end{array}$ & {$[€]$} & 24058.5 & 22758.8 & 22541.9 & 19936.1 & 28135.8 \\
\hline
\end{tabular}


Table 5. Sensitivity analysis to fouling rate

\begin{tabular}{|c|c|c|c|c|c|c|}
\hline \multicolumn{3}{|l|}{ Parameter } & $\begin{array}{c}\text { Joint } \\
\text { Optimization } \\
\text { k=0.33 }\end{array}$ & $\begin{array}{c}\text { Joint } \\
\text { Optimization } \\
\text { k=0.45 }\end{array}$ & $\begin{array}{c}\text { Joint } \\
\text { Optimization } \\
\text { k=-0.33 }\end{array}$ & $\begin{array}{c}\text { Joint } \\
\text { Optimization } \\
\mathrm{k}=-0.66\end{array}$ \\
\hline Shell diameter & $D_{s}$ & {$[\mathrm{~mm}]$} & 500.8 & 355.6 & 457.2 & 610.0 \\
\hline Baffle cut & $\mathrm{B}_{\mathrm{c}}$ & {$[\%]$} & 31 & 45 & 16 & 28 \\
\hline Number of baffles & $\mathrm{N}_{\mathrm{b}}$ & {$[-]$} & 11 & 4 & 3 & 16 \\
\hline Central baffle spacing & $\mathrm{L}_{\mathrm{bc}}$ & {$[\mathrm{mm}]$} & 318.0 & 355.6 & 457.2 & 122.0 \\
\hline Extremal baffles spacing & $\mathrm{L}_{\mathrm{bi}}, \mathrm{L}_{\mathrm{bo}}$ & {$[\mathrm{mm}]$} & 286.0 & 355.6 & 457.2 & 124.0 \\
\hline Pitch ratio & $\mathrm{L}_{\mathrm{tpR} \text { Ratio }}$ & {$[\%]$} & 1.32 & 1.29 & 1.33 & 1.42 \\
\hline Tubes ext. diameter & $\mathrm{D}_{\mathrm{t}}$ & {$[\mathrm{mm}]$} & 22.23 & 9.53 & 12.70 & 20.00 \\
\hline Tubes int. diameter & $D_{t i}$ & {$[\mathrm{~mm}]$} & 20.45 & 8.10 & 10.92 & 16.00 \\
\hline Tubes pitch & $\mathrm{L}_{\mathrm{tp}}$ & [mm] & 29.42 & 12.26 & 16.85 & 28.50 \\
\hline Tube layout angle & $\theta_{\mathrm{tp}}$ & [deg] & 45 & 30 & 30 & 90 \\
\hline Tube passes & $\mathrm{N}_{\mathrm{tp}}$ & {$[-]$} & 2 & 2 & 2 & 2 \\
\hline Tubes number & $\mathrm{N}_{\mathrm{tt}}$ & {$[-]$} & 193 & 660 & 586 & 315 \\
\hline Tubes length & $\mathrm{L}_{\mathrm{tt}}$ & {$[\mathrm{mm}]$} & 3802 & 1828 & 1879 & 2128 \\
\hline Flow velocity (tube-side) & $v_{t}$ & {$[\mathrm{~m} / \mathrm{s}]$} & 1.119 & 2.084 & 1.292 & 1.120 \\
\hline Flow velocity (shell-side) & $\mathrm{v}_{\mathrm{s}}$ & {$[\mathrm{m} / \mathrm{s}]$} & 0.336 & 0.959 & 0.463 & 0.637 \\
\hline Reynolds number (shell-side) & $\mathrm{Re}_{\mathrm{s}}$ & {$[-]$} & 11809 & 9561 & 7021 & 25954 \\
\hline Prandtl number (shell-side) & $\operatorname{Pr}_{\mathrm{s}}$ & {$[-]$} & 5.3 & 5.3 & 5.3 & 5.3 \\
\hline Reynolds number (tube-side) & $\mathrm{Re}_{\mathrm{t}}$ & {$[-]$} & 28456 & 20998 & 17546 & 22281 \\
\hline Prandtl number (tube-side) & $\mathrm{Pr}_{\mathrm{t}}$ & {$[-]$} & 5.5 & 5.5 & 5.5 & 5.5 \\
\hline $\begin{array}{l}\text { Convective heat transfer coef- } \\
\text { ficient (shell-side) }\end{array}$ & $\alpha_{\mathrm{s}}$ & {$\left[\mathrm{W} / \mathrm{m}^{2} \mathrm{~K}\right]$} & 3755.9 & 4547.7 & 4935.7 & 4655.6 \\
\hline $\begin{array}{l}\text { Convective heat transfer coef- } \\
\text { ficient (tube-side) }\end{array}$ & $\alpha_{t}$ & {$\left[\mathrm{~W} / \mathrm{m}^{2} \mathrm{~K}\right]$} & 5140.4 & 10171.4 & 6536.1 & 5401.5 \\
\hline $\begin{array}{l}\text { Overall heat transfer coeffi- } \\
\text { cient }\end{array}$ & $\mathrm{U}_{\text {dirt }}$ & {$\left[\mathrm{W} / \mathrm{m}^{2} \mathrm{~K}\right]$} & 1335.2 & 1965.8 & 1611.2 & 1662.8 \\
\hline Actual heat exchange area & $\mathrm{S}$ & {$\left[\mathrm{m}^{2}\right]$} & 50.56 & 35.11 & 42.76 & 41.13 \\
\hline Basic heat exchange area & $\mathrm{S}_{\text {clean }}$ & {$\left[\mathrm{m}^{2}\right]$} & 32.58 & 22.88 & 25.95 & 30.43 \\
\hline Additional heat exchange area & $\mathrm{S}_{\text {extra }}$ & {$[\%]$} & 36 & 35 & 39 & 26 \\
\hline Pressure drop (shell-side) & $\Delta \mathrm{p}_{\mathrm{s}}$ & {$[\mathrm{kPa}]$} & 7.18 & 11.60 & 5.88 & 16.85 \\
\hline Pressure drop (tube-side) & $\Delta \mathrm{p}_{\mathrm{t}}$ & {$[\mathrm{kPa}]$} & 6.71 & 28.48 & 9.12 & 5.63 \\
\hline Maintenance Kind & & & Mechanical & Chemical & Chemical & Mechanical \\
\hline Operating cost & $\mathrm{C}_{\mathrm{es}}$ & [€/yr] & 508.0 & 1621.6 & 580.7 & 733.4 \\
\hline Allowed fouling resistance & $R_{\text {f allowable }}$ & {$\left[\mathrm{m}^{2} \mathrm{~K} / \mathrm{W}\right]$} & 0.000267 & 0.000166 & 0.000234 & 0.000144 \\
\hline Cleaning interval & $\mathrm{T}_{\text {clean }}$ & {$[\mathrm{h}]$} & 6667 & 9273 & 6876 & 7050 \\
\hline Overall cleanings number & $\mathrm{N}$ & {$[-]$} & 5 & 4 & 5 & 5 \\
\hline Operating cost present value & $\mathrm{C}_{\mathrm{es}, \mathrm{tot}}$ & [€] & 1925.7 & 6147.1 & 2201.3 & 2780.2 \\
\hline Cleaning cost present value & $\mathrm{C}_{\text {clean,tot }}$ & [€] & 947.7 & 1516.3 & 1895.4 & 947.7 \\
\hline Capital investment & $\mathrm{C}_{\mathrm{I}}$ & [€] & 18095.9 & 15611.9 & 16863.6 & 16600.7 \\
\hline Cost & $\mathrm{C}_{\mathrm{I}}+\mathrm{C}_{\mathrm{es}, \text { tot }}$ & [€] & 20021.6 & 21759 & 19064.9 & 19380.9 \\
\hline Total cost & $\begin{array}{l}\mathrm{C}_{\mathrm{I}}+\mathrm{C}_{\mathrm{es}, \text { tot }}+ \\
\mathrm{C}_{\text {clean,tot }}\end{array}$ & {$[€]$} & 20969.3 & 23275.3 & 20960.3 & 20328.6 \\
\hline
\end{tabular}


Table 6. Sensitivity analysis to cleaning cost

\begin{tabular}{|c|c|c|c|c|c|c|}
\hline \multirow{2}{*}{$\begin{array}{l}\text { Parameter } \\
\text { Shell diameter }\end{array}$} & $\begin{array}{c}\text { Joint } \\
\text { Optimization } \\
\end{array}$ & $\begin{array}{l}\text { CCC: } 500 \\
\text { MCC: } 250 \\
\end{array}$ & $\begin{array}{l}\text { CCC: } 800 \\
\text { MCC: } 400\end{array}$ & $\begin{array}{l}\text { CCC: } 1000 \\
\text { MCC: } 500\end{array}$ & $\begin{array}{l}\text { CCC: } 500 \\
\text { MCC: } 1500\end{array}$ & $\begin{array}{l}\text { CCC: } 500 \\
\text { MCC: } 1500\end{array}$ \\
\hline & {$[\mathrm{mm}]$} & 355.6 & 355.6 & 406.4 & 406.4 & 323.8 \\
\hline Baffle cut & {$[\%]$} & 35 & 29 & 32 & 31 & 15 \\
\hline Number of baffles & {$[-]$} & 14 & 19 & 10 & 13 & 13 \\
\hline Central baffle spacing & {$[\mathrm{mm}]$} & 355.6 & 355.6 & 406.4 & 406.4 & 323.8 \\
\hline Extremal baffles spacing & $\mathrm{L}_{\mathrm{bi}}, \mathrm{L}_{\mathrm{bo}}$ & 355.6 & 355.6 & 389.0 & 406.4 & 323.8 \\
\hline Pitch ratio & $\mathrm{L}_{\text {tpRatio }}$ & 1.27 & 1.30 & 1.26 & 1.32 & 1.27 \\
\hline Tubes ext. diameter & {$[\mathrm{mm}]$} & 22.23 & 31.75 & 22.23 & 22.23 & 22.23 \\
\hline Tubes int. diameter & {$[\mathrm{mm}]$} & 20.45 & 28.45 & 20.45 & 20.45 & 20.45 \\
\hline Tubes pitch & {$[\mathrm{mm}]$} & 28.12 & 41.24 & 27.96 & 29.30 & 28.30 \\
\hline Tube layout angle & [deg] & 45 & 90 & 30 & 30 & 30 \\
\hline Tube passes & {$[-]$} & 1 & 1 & 2 & 2 & 2 \\
\hline Tubes number & {$[-]$} & 107 & 47 & 158 & 144 & 93 \\
\hline Tubes length & {$[\mathrm{mm}]$} & 5384 & 7162 & 4486 & 5740 & 4583 \\
\hline $\begin{array}{l}\text { Flow velocity } \\
\text { (tube-side) }\end{array}$ & {$[\mathrm{m} / \mathrm{s}]$} & 1.009 & 1.187 & 1.367 & 1.500 & 2.322 \\
\hline $\begin{array}{l}\text { Flow velocity } \\
\text { (shell-side) }\end{array}$ & {$[\mathrm{m} / \mathrm{s}]$} & 0.593 & 0.704 & 0.908 & 0.630 & 1.313 \\
\hline $\begin{array}{l}\text { Reynolds number (shell- } \\
\text { side) }\end{array}$ & $\operatorname{Re}_{\mathrm{s}}$ & 17587 & 32974 & 19018 & 16275 & 29103 \\
\hline Prandtl number (shell-side) & $\operatorname{Pr}_{\mathrm{s}}$ & 5.3 & 5.3 & 5.3 & 5.3 & 5.3 \\
\hline Reynolds number (tube-side) & $\mathrm{Re}_{\mathrm{t}}$ & 25664 & 41994 & 34760 & 38139 & 59055 \\
\hline Prandtl number (tube-side) & $\mathrm{Pr}_{\mathrm{t}}$ & 5.5 & 5.5 & 5.5 & 5.5 & 5.5 \\
\hline $\begin{array}{l}\text { Convective heat transfer co- } \\
\text { efficient (shell-side) }\end{array}$ & {$\left[\mathrm{W} / \mathrm{m}^{2} \mathrm{~K}\right]$} & 4500.6 & 5381.5 & 4310.6 & 4351.7 & 6898.2 \\
\hline $\begin{array}{l}\text { Convective heat transfer co- } \\
\text { efficient (tube-side) }\end{array}$ & {$\left[\mathrm{W} / \mathrm{m}^{2} \mathrm{~K}\right]$} & 4732.8 & 5044.1 & 6032.8 & 6497.6 & 9218.5 \\
\hline $\begin{array}{l}\text { Overall heat transfer coeffi- } \\
\text { cient }\end{array}$ & {$\left[\mathrm{W} / \mathrm{m}^{2} \mathrm{~K}\right]$} & 1620.0 & 1936.4 & 1397.2 & 1192.5 & 2334.0 \\
\hline Actual heat exchange area & {$\left[\mathrm{m}^{2}\right]$} & 39.85 & 33.34 & 48.93 & 57.21 & 29.44 \\
\hline Basic heat exchange area & {$\left[\mathrm{m}^{2}\right]$} & 29.17 & 26.28 & 28.11 & 27.08 & 17.93 \\
\hline $\begin{array}{l}\text { Additional heat exchange } \\
\text { area }\end{array}$ & $S_{\text {extra }}$ & 27 & 21 & 43 & 53 & 39 \\
\hline Pressure drop (shell-side) & {$[\mathrm{kPa}]$} & 18.42 & 22.93 & 13.02 & 14.09 & 49.99 \\
\hline Pressure drop (tube-side) & {$[\mathrm{kPa}]$} & 3.57 & 4.35 & 10.77 & 15.86 & 28.86 \\
\hline Maintenance Kind & 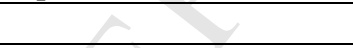 & Mechanical & Mechanical & - & - & - \\
\hline Operating cost & $\begin{array}{ll}\mathrm{C}_{\mathrm{es}} & {[€ / \mathrm{yr}]} \\
\end{array}$ & 684.7 & 847.9 & 858.2 & 1119.7 & 2727.7 \\
\hline Allowed fouling resistance & $\begin{array}{ll}\mathrm{R}_{\mathrm{f} \text { allowable }} & {\left[\mathrm{m}^{2} \mathrm{~K} / \mathrm{W}\right]} \\
\end{array}$ & 0.000161 & 0.000105 & 0.000294 & 0.000433 & 0.000161 \\
\hline Cleaning interval & $\mathrm{T}_{\text {clean }} \quad[\mathrm{h}]$ & 6956 & 6803 & 40007 & 40004 & 49434 \\
\hline Overall cleanings number & $\mathrm{N}$ & 5 & 5 & 0 & 0 & 0 \\
\hline Operating cost present value & $\mathrm{C}_{\mathrm{es}, \mathrm{tot}}$ & 2595.5 & 3214.2 & 3253.2 & 4244.5 & 10340.1 \\
\hline Cleaning cost present value & $\mathrm{C}_{\text {clean,tot }}$ & 947.7 & 1516.3 & - & - & - \\
\hline Capital investment & $\mathrm{C}_{\mathrm{I}}$ & 16393.2 & 15314.0 & 17842.2 & 19115.4 & 14646.4 \\
\hline Cost & $\mathrm{C}_{\mathrm{I}}+\mathrm{C}_{\mathrm{es}, \mathrm{tot}}$ & 18988.7 & 18528.2 & 21095.4 & 23359.9 & 24986.5 \\
\hline Total cost & $\begin{array}{l}\mathrm{C}_{\mathrm{I}}+\mathrm{C}_{\mathrm{es}, \mathrm{tot}} \\
+\mathrm{C}_{\text {clean,tot }}\end{array}$ & 19936.4 & 20044.5 & 21095.4 & 23359.9 & 24986.5 \\
\hline
\end{tabular}




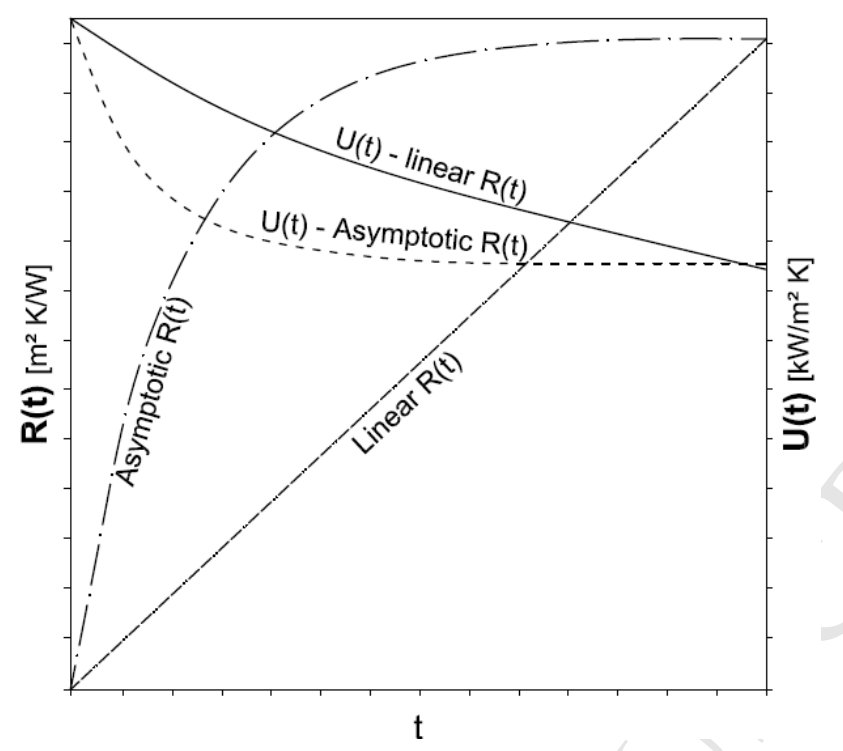

Figure 1 - Different kind of fouling trends (adapted from [33]).

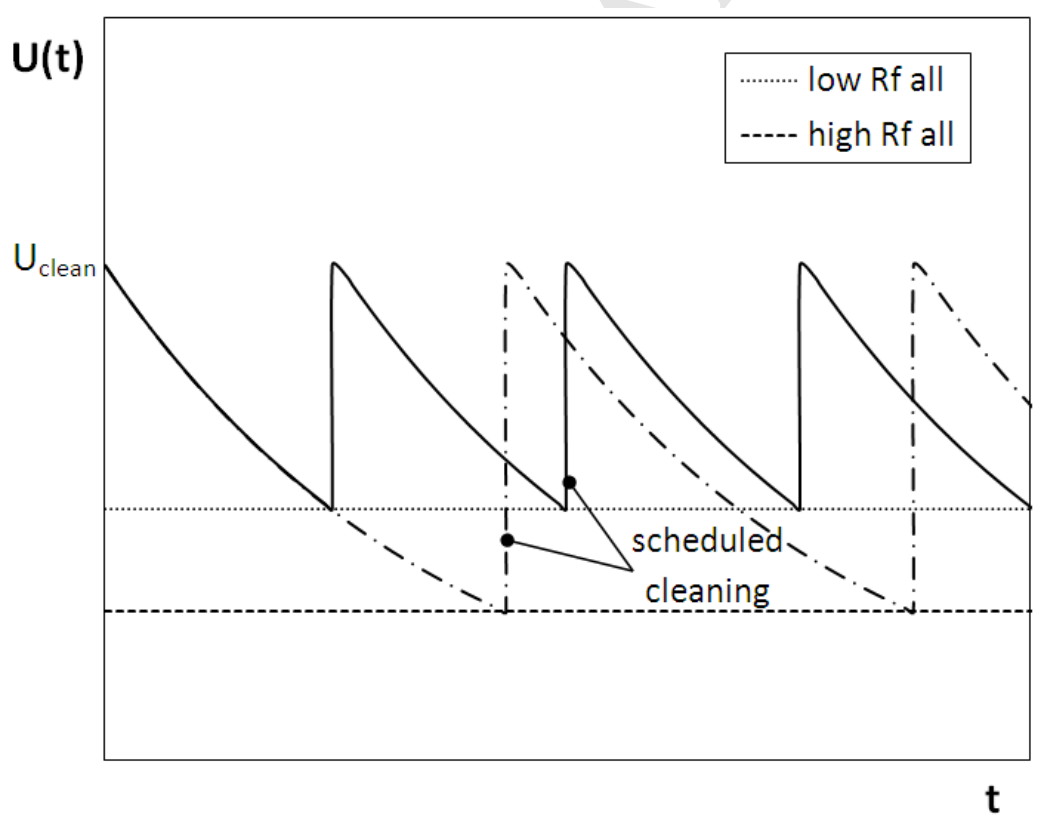

Figure 2- Influence of allowed fouling resistance on cleaning policy. 


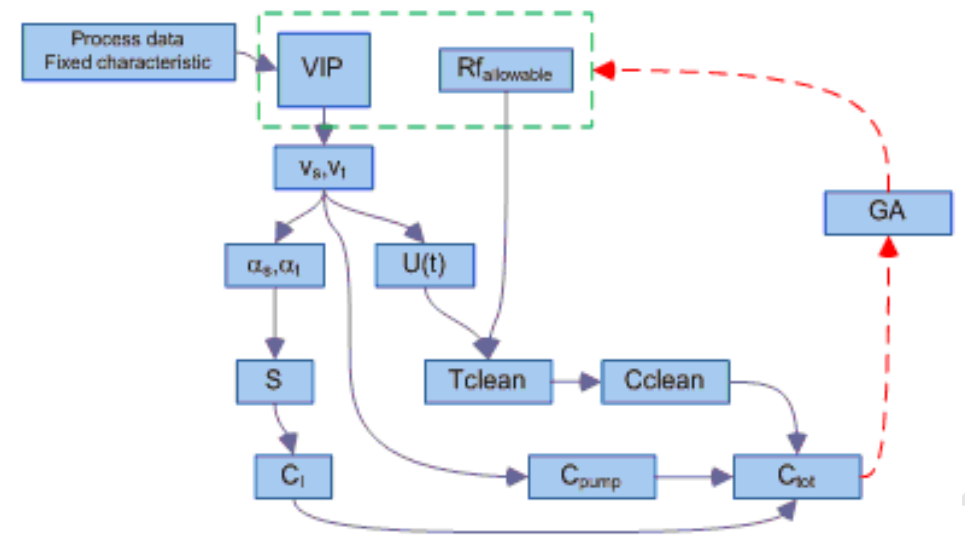

Figure 3 - Flow chart of optimization procedure using GA and considering maintenance.

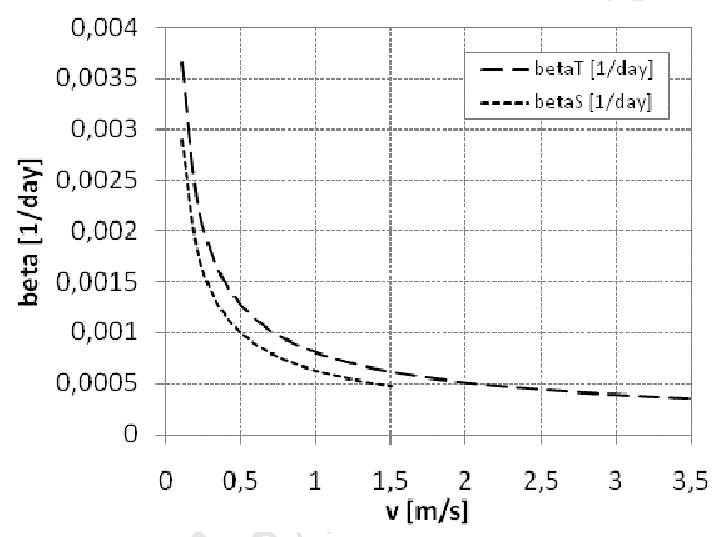

Figure 4 - Trend of $\beta$ vs flow velocity tube-side (betaT curve) and shell-side (betaS curve).

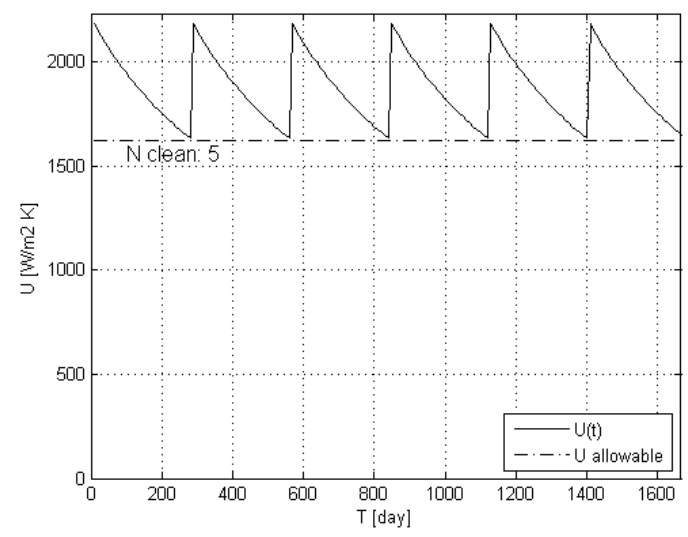

Figure 5 - U trend through 5 years for the "Joint Optimization" exchanger. 


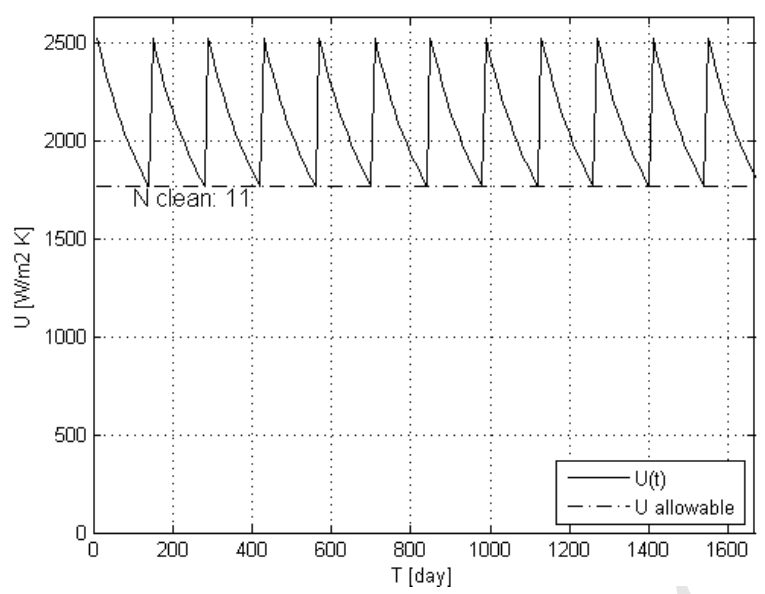

Figure 6 - U trend through 5 years for the "TGA2" exchanger.

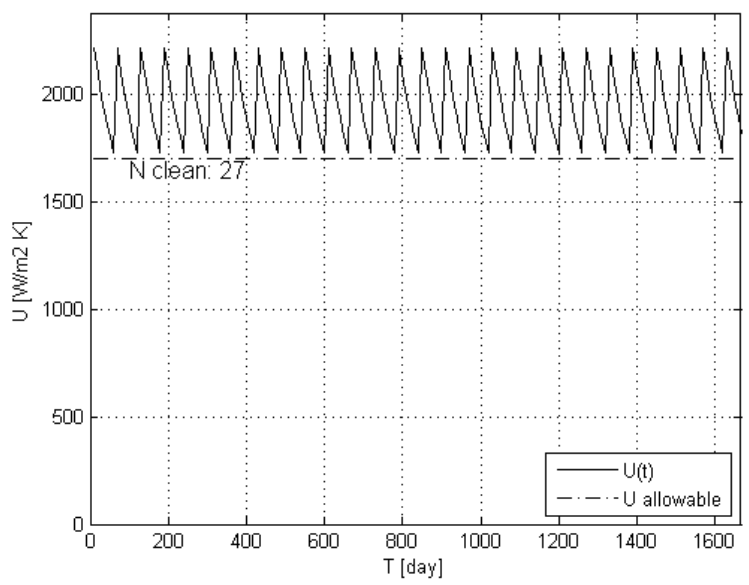

Figure 7 - U trend through 5 years for the "Hybrid TGA" exchanger. 